\title{
Il Milione. The first 14 years of ERC funding to human past studies (SH6): an Italian perspective
}

\author{
Giancarlo Lago ${ }^{1} \&$ Andrea Di Renzoni ${ }^{2}$ \\ ${ }^{1}$ Università di Roma “La Sapienza”, Dipartimento di Scienze dell'Antichità \\ ${ }^{2}$ Istituto di Scienze del Patrimonio Culturale - CNR
}

\begin{abstract}
This article addresses European Research Council (ERC) grants in the Archaeology and History panel (SH6). The study was conducted by considering the first two cycles of ERC funding (2007-2020). We introduce to eligibility criteria and evaluation process involved in ERC calls. We show the results of the analysis in terms of most awarded 'countries' per call (Starting Grant, Consolidator Grant, Advanced Grant), the profiles of researchers and the main research subjects of 360 granted funding. The inquire is extended to a systematic analysis regarding the profile of scientific members of the commissions (480 scholars) employed to evaluate the proposals. The outcome is that Italian institutions underperforming compared to other major European countries; the success rate of 'Italian' proposals is lower than the European average; young Italian researchers very rarely obtain Starting Grants. This is, we believe, partly due to some policies currently still in place - even if no longer sustainable - in Italian universities. There is some correlation between most awarded institutions (by country) and most employed panelists. In the final part, we show the main trending topics of ERC projects.
\end{abstract}

Keywords: ERC; Social Sciences \& Humanities; Archaeology; History; Research Trend topic; Italian university.

\section{Introduction}

First two cycles of ERC grants have recently concluded with more than ten-thousands fully funded projects and ca $€ 20.6$ billion invested in Research and Development (R\&D). The European Research Council (ERC) was the most funded programme in 'Horizon 2020 ' and, since a new cycle of European research funding has begun, it is a good time to provide a report of principal European countries performance.

The starting point of the second section is an opinion article that discusses the effects that ERC grants have on both on the academic careers of young researchers and on internal 
departmental policies. In the third and fourth sections, we explain the data collection methods and criteria of data collection, followed by the main results, both from Horizon 2020 and from the first fourteen years of ERC. The main focus is the Social \& Humanities domain (SH), in particular the 'Archaeology and History' panel (SH6). In the last part we comment the results with special attention to the Italian case, due to the worst performance of the Institutions among the large countries. Lastly, we discuss some of the criticism that arose in the second part as they are not absolutely confirmed by the data analysis.

\section{Premise}

A cause-effect mechanism: a criticism to ERC grants by W alter Lapini

On January 14 - 2020, on the website of the Italian journal 'Corriere della Sera' was published an opinion article: Quei superfinanziamenti che sconvolgono gli atenei. The author - Walter Lapini, full professor of Greek literature at the University of Genoa sustained harsh criticism of the ERC grants system.

The declared goal of the European Research Council is to reward the 'excellence'. However, according to Walter Lapini, the current funding policy supports an extreme collection of resources to very few researchers, at the expense of a less profit to a higher number of researchers. The ERC winner - especially if young and still in search of a permanent position - is usually hired at the Host Institution. Since humanities departments constantly suffer from money shortage, they can't turn down the new injection of cash, even if the condition is a professor position in exchange. The Universities have such a need of resources that they force the system - with no exclusion of expedients - to accommodate any request from the ERC winner. In this way, the normal and regular planning of the department is definitely compromised. The most penalized are those researchers who were patiently waiting their turn, bypassed over by the inexorable 'advancement of the Million' (of funding ed.).

At the end, Walter Lapini doubts about the real quality of the awarded researcher and the proposed research. The formers have the only merit to having been able to speak the language the commission wants - including trend topic words such as 'gender' and 'sustainability' -, and the latter evaluated by commissions whose members are not always fully competent on the specific topics. The commissions - writes Walter Lapini - are usually formed by specialists from other disciplines and do not have a clear idea of the study subject they are judging on or, worse, their idea is biased.

\section{Reward the 'excellence': a reaction to Lapini's arguments}

In January 2020, a few days after the first, a second article entitled "Finanziamenti Erc, il coraggio di premiare l'eccellenza" was published on the website of 'Corriere della Sera'. It is a response article written by Francesco C. Billari (Full Professor of Demography at the Bocconi University), and Gianmario Verona (Full Professor and Chancellor at the Bocconi University). The authors emphasize the fair accessibility of the competition, involving different calls aimed at both early-stage researchers as well as Professors with a permanent position. Moreover, the ERC funding is something in addition to (scarce) public funding without replace or steal resources. Finally, according to the authors, ERC 
grant winners are talented researchers and the amount of financing is commensurate with his/her research ambition.

Further objections to the Lapini's arguments came from Gianluca Briguglia (associate Professor at the Ca' Foscari University) who published a response article for 'Il Post' titled "Il ritorno della casta dei poverini?". The author highlights the positive approach to research promoted by ERC, with bottom-up projects and the opportunity to (temporarily) hire $\mathrm{PhD}$ candidates, post-docs and fellowship researchers at no costs for the Host Institution. However, the main criticism of Lapini concerns the recruitment policy that Italian Universities reserve to the ERC winners. The latter - harshly criticized by W. Lapini - is considered a good strategy to attract (and hold) researchers who could otherwise bring their project (and related money) elsewhere, impoverishing Italian research.

Using both official data published by European Institutions and new data we collected to the purpose, we intend to add complexity to this debate and to test, by means of measurable parameters, the suggestions described above.

\section{The reasons for this research}

Walter Lapini's article has had a good diffusion on Social Networks - at least among the people attending Universities - triggering a heated debate within the academy. The questions posed by the author primarily involve two aspects of the Italian academic structure that, according to the author, reluctantly had to be conformed to the European context: scholar recruitment and research quality, the latter being considered unrelated (or inversely related!) to the success rate in competing for European funding, such as ERC grants.

The impression is that there is a generational conflict in evaluating European funding opportunities. If on the one hand, the European grant weakens the decision-making power of Professors and Department Chiefs, on the other hand it gives to young researchers the possibility to impose their selves immediately and without the slow and ordinary recruitment process.

Contrary to Lapini's assertions we believe that competitiveness is closely related to structural factors and to the quality of research (and researcher), whatever it may be. We also believe that, in order to understand the changes occurred in the last two decades in the Italian academic politics, the structure of the European research framework should be explored, and that ERC-grant distribution analysis could shed light on this matter.

\section{What is ERC?}

The European Research Council (ERC) is the first public body that supports top researchers within the European Union institutions (EU). It was established in 2007 within the 7th Framework Programme, with a budget of ca $€ 7.5$ billion. Funds for the ERC programme has steadily increased over the last fourteen years, reaching ca $€ 13.1$ billion budget in the latest Horizon 2020. The challenge for the ERC is to bridge the gap with non-EU institutions and researchers creating a European research area (Winnaker 2008). Calls and applicants

Principal Investigators (PIs) of all nationalities and all disciplines are welcome as ERC applicants. They have a sole requisite for excellence, and their projects should be innovative and cutting-edge research. All the candidates submit a five-year long research 
project to be carried out in a European (or associated country) Host Institution (HI). ERC is organized into three main domains: Physical Sciences \& Engineering (PE), Life Sciences (LS) and Social Sciences \& Humanities (SH), divided in panels. There are three main calls, based on different career stages of the applicants: Starting Grant (StG), Consolidator Grant (CoG), Advanced Grant (AdG). While Starting and Advanced Grant respectively existed since 2007 and 2008, the Consolidator Grant was added in 2013.

\begin{tabular}{|c|c|c|c|}
\hline Call & $P h D$ & $C V$ & Financing \\
\hline StG & Yes (from 2 to 7 years before) & 5 best peer reviewed publications & up to $€ 1,5$ million \\
\hline $\mathrm{CoG}$ & $\begin{array}{l}\text { Yes (from } 7 \text { to } 12 \text { years } \\
\text { before) }\end{array}$ & $\begin{array}{l}10 \text { best peer reviewed } \\
\text { publications }\end{array}$ & up to $€ 2$ million \\
\hline $\mathrm{AdG}$ & Not required & last 10 years milestones & up to $€ 2,5$ million \\
\hline
\end{tabular}

Table 1. Summary scheme of main ERC calls

The profile of the applicant matters. It is emphasized the independence of talented postdocs and early-stage researchers, respectively competing for Starting and Consolidator grants. Part of the evaluation involves international and peer-reviewed publications, primarily those that do not include his/her $\mathrm{PhD}$ supervisor. It is mandatory at least one publication without $\mathrm{PhD}$ supervisor for Starting Grant's candidates and 'several' for Consolidator Grants applicants. The Advanced Grant call is more focused on milestones and influential research. In addition, contribution in promoting the career of young scholars. In recent years, ERC has added two more grants: Synergy Grant and Proof of Concept. The first one is addressed to joint groups of researchers from different Institutions. Proof of Concept is indeed a further funding for ERC winners aimed at commercializing their ideas. In this study we will deal only with the three main individual grants (StG, CoG, AdG).

\section{The evaluation processes and the board's composition}

Each domain has a number of panels - now twenty-seven in total - composed of a scientific board. The panels operate the first step of evaluation, based on the originality of the proposed research and profile of candidate. Then, the project is evaluated through an international peer-review process and the quality is also assessed by external reviewers, experts in the research field. In the not uncommon case of interdisciplinary proposals, experts from other panels are involved in the process. After successfully passing these phases, Starting and Consolidator candidates are interviewed by panel members. The second step of the Advanced Grant evaluation is indeed consisting of a further and more in-depth assessment of the proposal (König 2016). The names of the panel members are kept anonymous until the end of evaluation process. Differently, the names of Chairs for each panel are in the public domain.

A new challenge: are European researchers, globalist enough?

The ERC is a portable research grant. Therefore, the winner can change his/her Host Institution after obtaining it. The $\mathrm{HI}$ is obligated to hire the PI, at least as long as the ERC 
goes on. Since the Universities have a constant need to gain new funding and hosting an ERC is prestigious, the PIs have the bargaining power to get the best possible conditions. In this sense, the early stages career grantees achieve an early independence previously unknown in the academic system (König 2016: 160).

At the end of the premise some questions arise. The ERC was created with the stated intention to challenge the hegemony of non-EU research from a worldwide perspective. To achieve this result, a new concept was introduced: the 'European Research Area' (Nowotny 2009; Winnacker 2009). The mobility of researchers between European countries is probably the most important indicator of whether the desired 'European Research Area' is becoming a reality. In section four and five we show how far this goal is still to be realized. There are a few northern-European countries (besides UK) that are able to attract enough foreign ERC winners. A number of factors stand in the way of real and more effective interchange area and the direction of movement is, at least for $\mathrm{SH}$ panel, strongly oriented from Southern to Northern Europe. In the discussion we offer some suggestions based on the analysis of SH6 network.

\section{Materials and Methods}

We approached the thematic of ERC grant distribution analysis at several scales: 1) the broadest picture relating to the nations and their research politics, and research institutions that act as Host Institutions in ERC all domains; 2) a medium scale relating to the $\mathrm{SH}$ panel, and 3) the narrowest relating the PIs and research subjects of the SH6 ERC projects, and the composition of SH6 panels.

\section{Countries and Host Institutions}

Countries have been classified according to 1) their economic magnitude, calculated based on the Gross Domestic Products (GDPs) and 2) to their 'attitude towards research', calculated as the expenditure for Research activities $(\mathrm{R} \& \mathrm{D})$ that each country invests. The correlation between these values and the grant awarded by each country has been analysed. Further, 3) we explored and measured for each country the ability to attract foreign scholars by defining the quantity of PIs that from a country moved to another during critical steps of their formation: the place of birth compared to the countries where the $\mathrm{PhD}$ has been achieved, and the country where the ERC grant has been obtained. Data on this 'attraction index' were obtained from the examination of more than $360 \mathrm{CVs}$, freely available on institutional and social network profiles (e.g., academia.edu, ResearchGate, ORCID page, etc.) of ERC grantees. The data were primarily analysed by a network analysis to explore the capacity index and the connectedness across different countries. Host Institutions have been analysed mainly by the number of grants achieved.

\section{Formation and networks of Principal Investigators}

To draw the 'average profile' of the awarded PIs, we considered 1) a set of 'structural' parameters, such as gender and country of provenance/formation, and 2) using the same data considered to define the 'attraction index' of the countries, we tried to define how mobility during the formation process of the PIs influenced their competitivity. The 'mobility index' has been defined at the country-level, number of countries where a scholar 
studied during his/her academic career, and at the University-level, number of universities (or research institutions) linked to each PI. The subjects of the award-winning projects were analysed based on the most recurrent words taken from the summaries of the projects of the SH6 sector, trying to enucleate the terms, the so called 'buzzwords', that characterize the research trends.

\section{Panel members' institutions and main research topic}

In order to learn more about who evaluates projects we conducted a survey on panellists' public CVs obtaining key information on 1) panellists' nationality and affiliation they had at the time of the call, and 2) main research area of interest. The latter is based both on the education and topic of each panellist's major publication. All SH6 panels from 2008 onward were considered.

\section{Data sources}

Data were collected from institutional sites: 1) ERC data and panels were retrieved from the dedicated site ${ }^{1}$ and from the ERIS (European Research Institute) web page, dedicated to $\mathrm{ERC}^{2}$; 2) country data came mainly from Eurostat site ${ }^{3}$. Data come also from other sources such as EU reports and papers dedicated to the topic. Data about PIs and panellists CVs were collected from our survey and - as stated - pertain only SH6 funded projects. These data relate to the place of birth, universities attended and the number of publications at the moment of the grant achievement.

An additional set of data consists of the results of a survey we conducted among participants of our personal academic network (colleagues, students etc., mainly from the Sapienza University of Rome), to assess student and scholars' awareness of certain funding opportunities. We believe that the awareness of grant chances is a crucial factor, not only influencing academic careers, but a good proxy for the involvement of the Italian institution in the European research system.

\section{Data analysis}

\section{Countries, Host Institutions and applicants}

Wide-scale analysis: contributors and beneficiaries

All the EU funding programs are based on the annual fees that individual countries make. Contributions are based on the internal economy, being proportional to GDP, and implying larger countries pay more. A European programme like Horizon 2020 only allocates funds based on the merit of proponents (and proposals), thus there is no correlation between fees paid and the funds every country obtains. In this special ranking, considering only EU members in the period 2014-2019, Germany, France and Italy record the worst gain-loss balance (e.g., Germany contributes 20,5\% of the European budget, gaining 14,5\% of Horizon 2020 funds, hence recording a loss of $6 \%$ ). Conversely, small

\footnotetext{
${ }^{1}$ https://erc.europa.eu/

2 https://webgate.ec.europa.eu/erceris/application/static/eris/Statistics

3 https://ec.europa.eu/eurostat/data/database
} 
countries like Belgium and Netherlands record, in proportion, a good profit. The UK is the only large country with a positive gain \& loss balance, partly due to the 'UK rebate'.

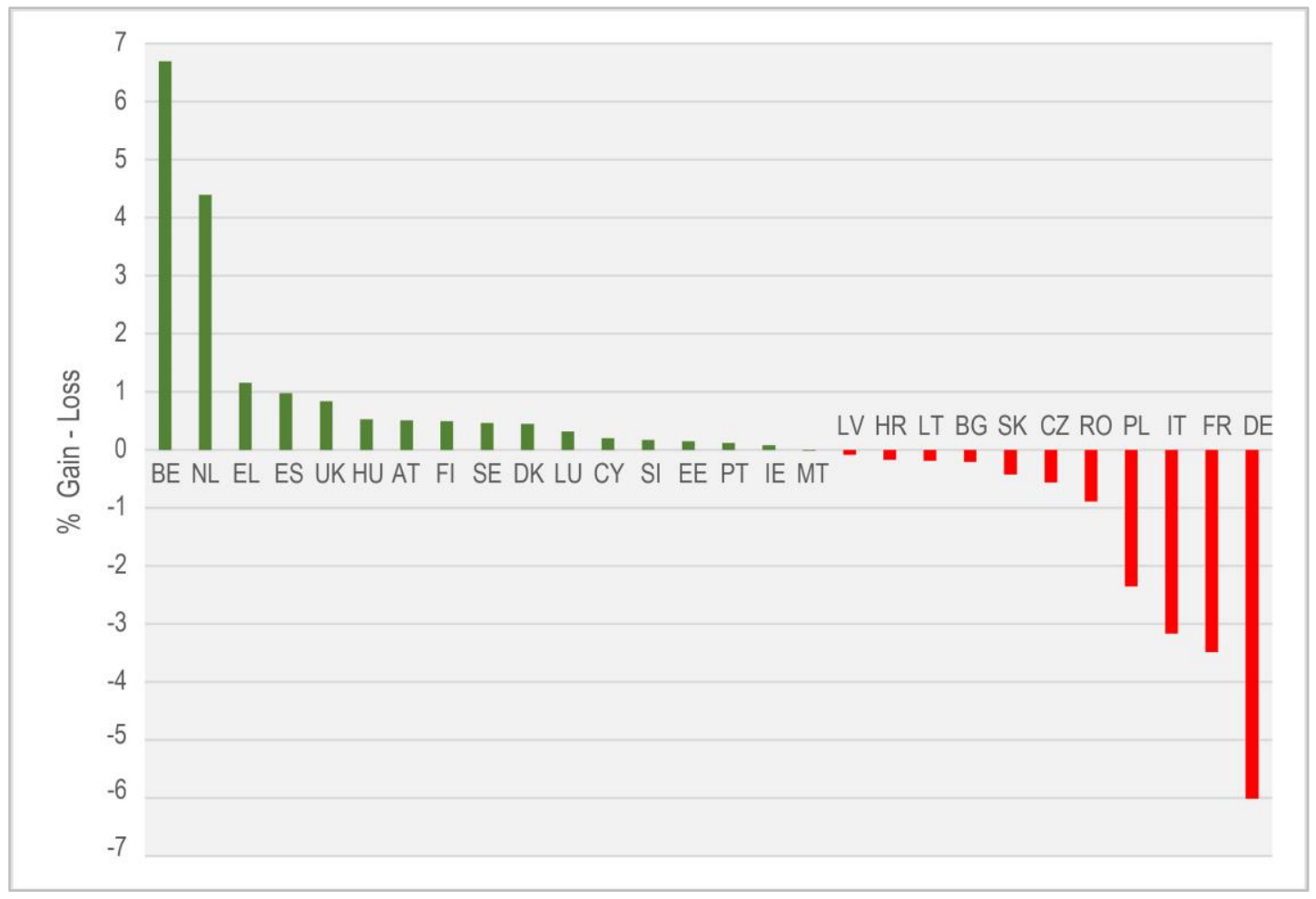

Figure 1. The funding each EU member country obtained by Horizon 2020 (2014-2020), expressed in percentage of the total amount constitute the 'gains'. The fees each EU member country paid (2014-2019) are expressed in percentage of the total amount and constitute the losses. The Figure shows the positive/negative balance each EU country has.

Wide-scale analysis: GDP and R $\odot D$ vs ERC awarded.

While the larger (and richer) countries have a negative gain-loss balance, they seem to be able to get most of ERC grants. At least, it is true for Germany and France. The United Kingdoms are the leader country for ERC awarded, while the Italians HIs has recorded by far the worst performance. Despite a higher GDP amount, Italy is less performative than smaller countries like Netherland, Spain, Switzerland and Israel. There is, in fact, a third variable to consider: the internal $R \& D$ funding. Low public investment in the $R \& D$ sector strongly influences the Italian possibilities of success in the European competition, making Italian HIs both less attractive and less competitive than others. More generally, GDPs and number of ERC awarded seem strictly correlated. Two trends can be underlined, a 1:2000 ratio, where the largest counties are found and a 1:1000 ratio, describing the best performing countries. The UK, among the largest countries is closer to the latter trend, while Italy (and Spain) is below the line of the second trend. 


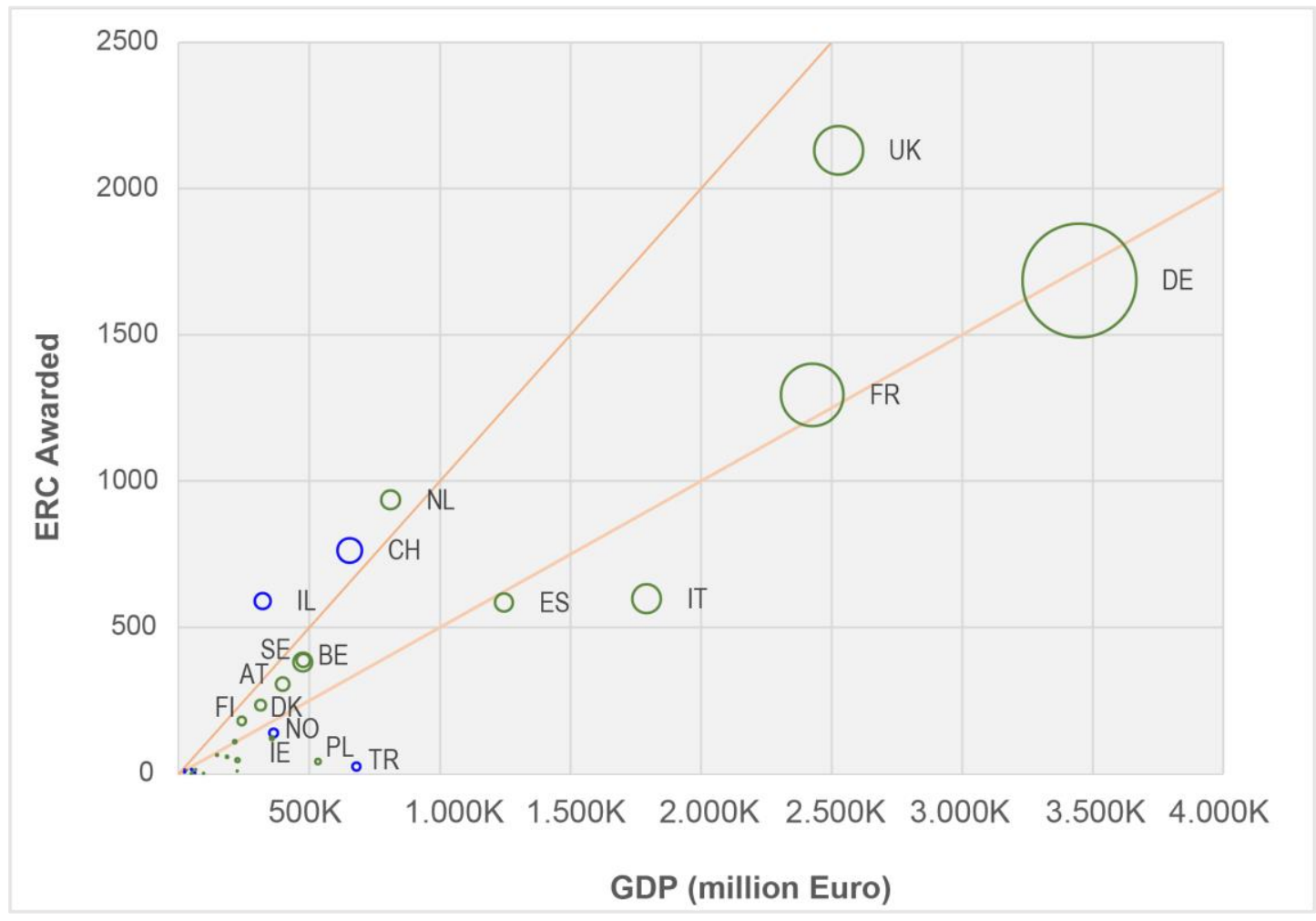

Figure 2. Scatter plot showing GDP, ERC awarded and R\&D expenditure for each country. The magnitude of the circles indicates the R\&D expenditure. Green circles indicate EU countries, blue circles indicate ERC associated countries.

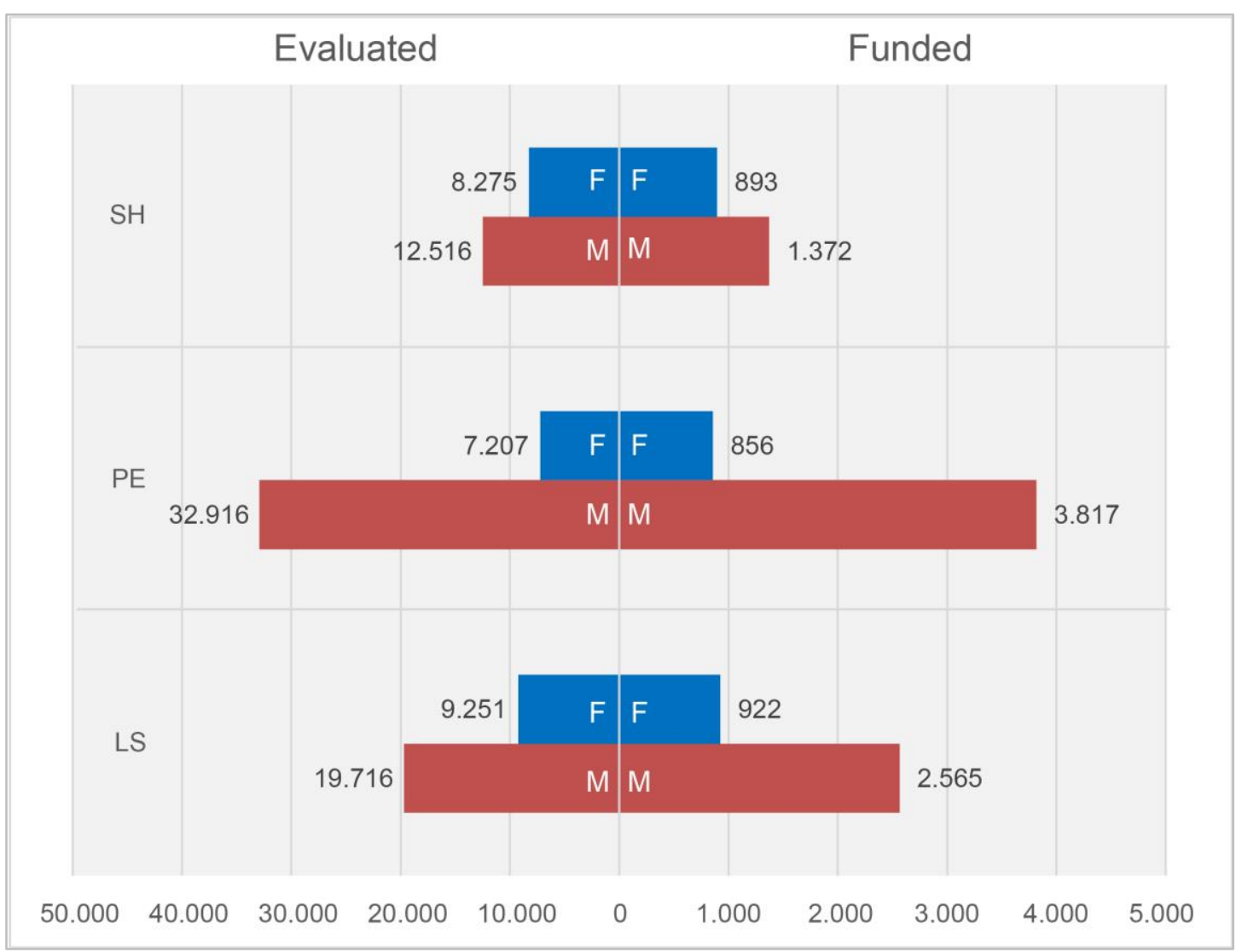

Figure 3. Bar diagram showing the number of evaluated and funded projects divided by panels and gender. 


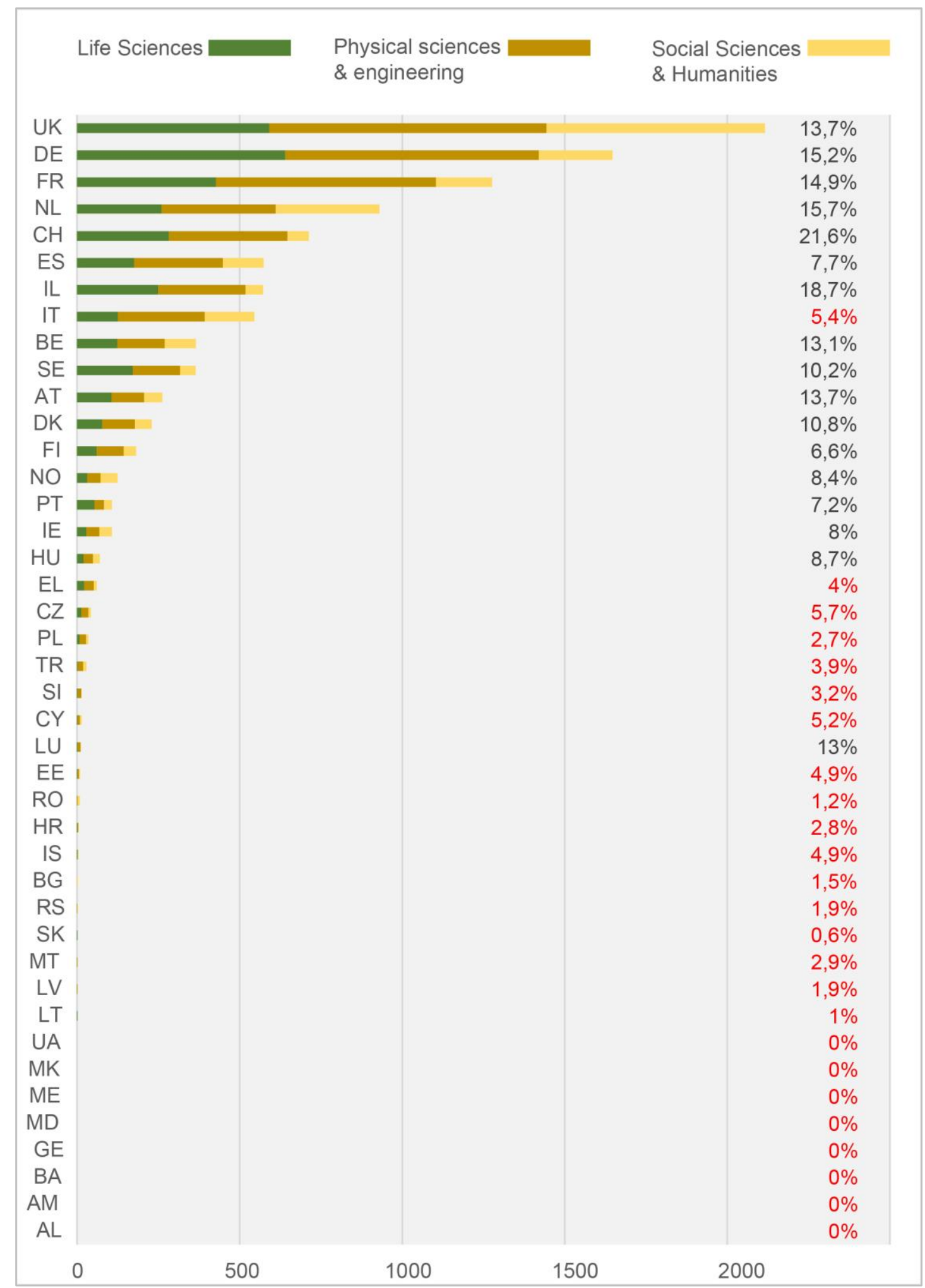

Figure 4. Bar diagram showing number of ERC awarded by each country divided by panels. Percentages indicate the success rate.

Wide-scale analysis: gender gap and success rate

The probability that a project can be financed is approximately the same for each domain, having a similar success rate (11\% in SH; 11,6\% in PE; 12,1\% in LS). Taking into account 
the gender of the Principal Investigators, a clear gender gap emerges, leaning in favor of males. It is a declared will of ERC and EU to promote the gender balance in the institutions. However, the ERC data show a marked difference still exists to male PIs versus female PIs, reflecting roughly the same Male-Female ratio that the evaluated projects have. The low participation of female researchers is not imputable to ERC selection criteria, but rather to structural and cultural issues favoring the marked gender difference observable (Fig. 3). The Male-Female ratio is definitely higher in PE and LS panels (the bigger ones), and less accentuated - still high - in the SH panel.

Wide-scale analysis: ERC awarded by domain and success rate per country.

Over the past fourteen-years (2007-2020), the UK institutions have been the most granted, followed by Germany and France (Fig. 4). Elaborating official data of evaluated and funded proposals - whose nationality is based on the HI provenance - it is possible to calculate the average success share, which is attested to around $6,2 \%$. UK, Germany, France and Netherland are all grouped within 2 points - ranging from 13,7\% and 15,7\% - of success share. The highest success share is recorded by two non-EU members, both associated countries: Switzerland and Israel. Spain and Italy underperform, with the latter below the overall average. Another interesting fact arise by observing in detail the number of funded projects per domain. The difference among UK and Germany is largely determined by the highest number of SH grants hosted by the former country. Taking the SH domain into consideration, British HIs are undisputed leaders, while associated countries like Switzerland and Israel are surpassed by Italy and Spain (Fig. 5).

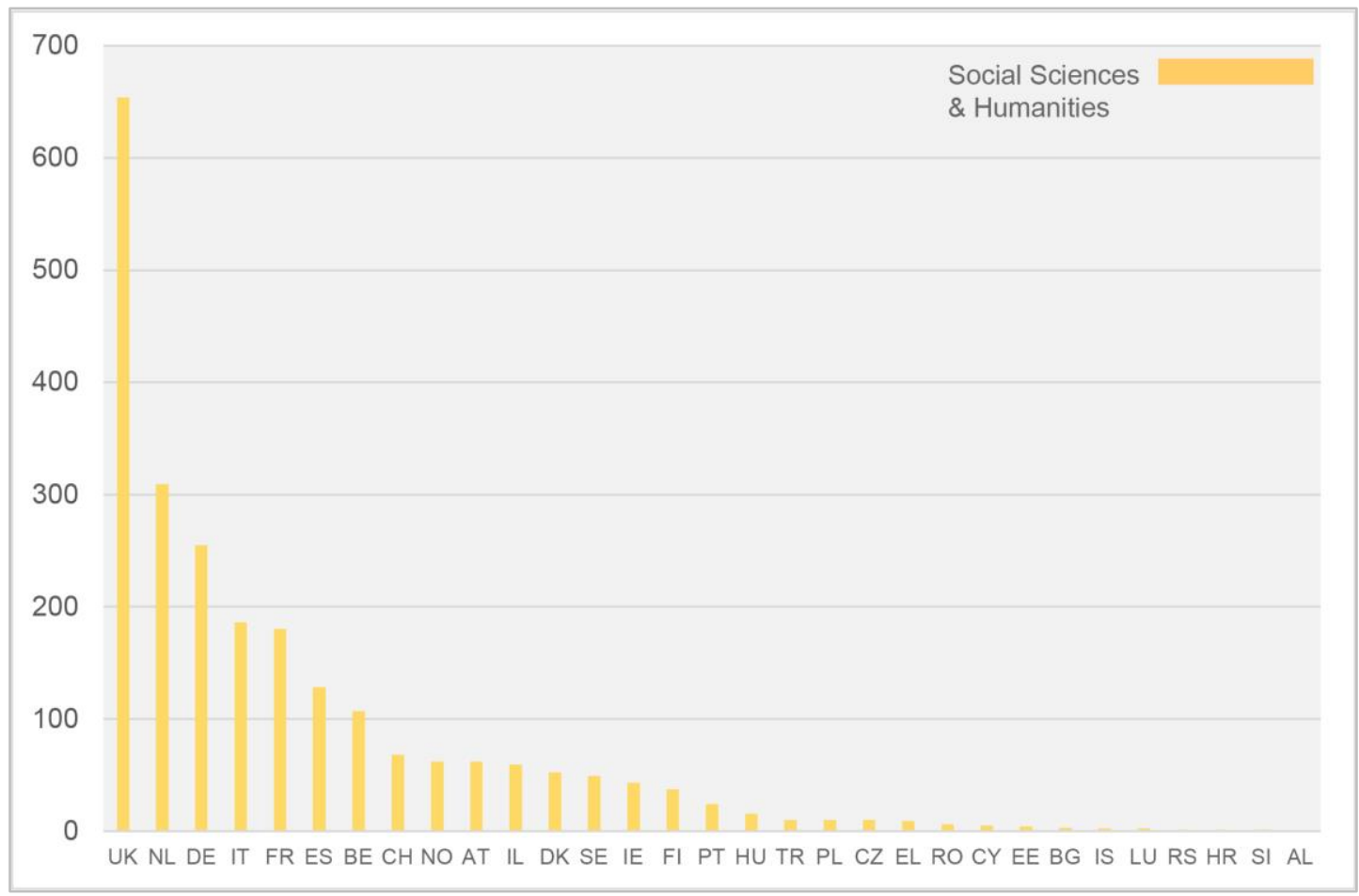

Figure 5. Bar diagram showing the number of ERC awarded by each country in the SH panel. 
Medium-scale analysis: the geography of competitivity in SH6

The data analysis for SH6 shows how uneven is the grants distribution in Europe. The most competitive HI are largely concentrated between Belgium/Netherland and the British Isles, while several hotspots are located in Central Europe. The Iberian, Scandinavian, eastern, and southern countries have just a few Institutions hosting grants (Fig. 6).

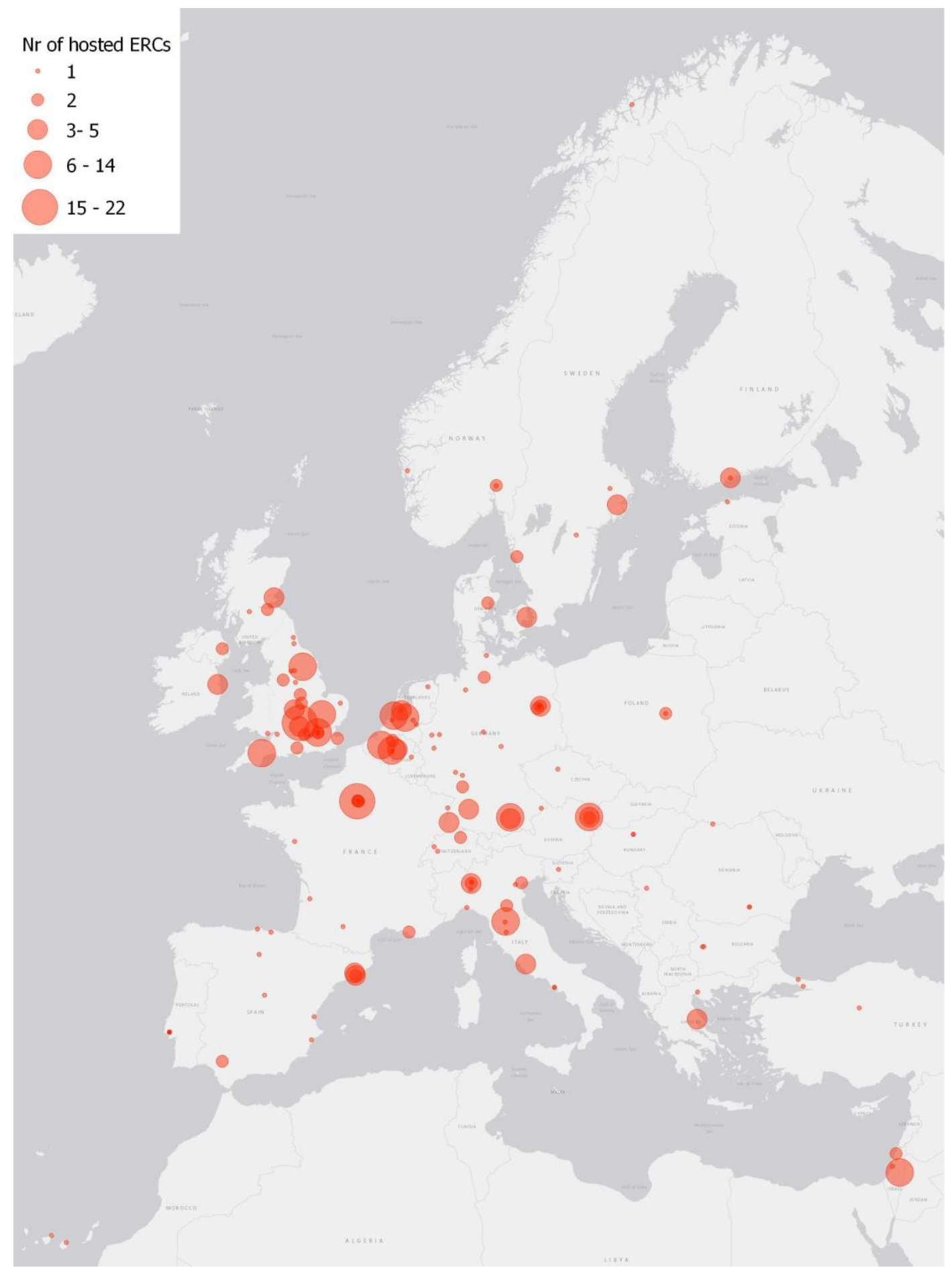

Figure 6. Map showing the distribution of the Institutions that host ERC projects. Where the same Institution has more locations, the dot is placed in correspondence of the central Office. 
Medium-scale analysis: main ERC calls in SH6

Within the SH6 panel - involving archaeological and historical disciplines - the UK institutions result far over all the others. Notably, the proportion that the diverse programs have (StG, CoG, AdG), is quite uneven among different countries. The UK is out of the scale, resulting in the first position in every programme. Among the countries with more grants obtained, Italy ranks second position for the Advanced Grants, whilst is sixth for Consolidator and Starting Grants. Conversely, Netherland and Belgium are strongly oriented towards early-stage carriers funding, respectively fourth and fifth. Starting Grants constitute the principal funding programme also for Germany and France (Fig. 7).

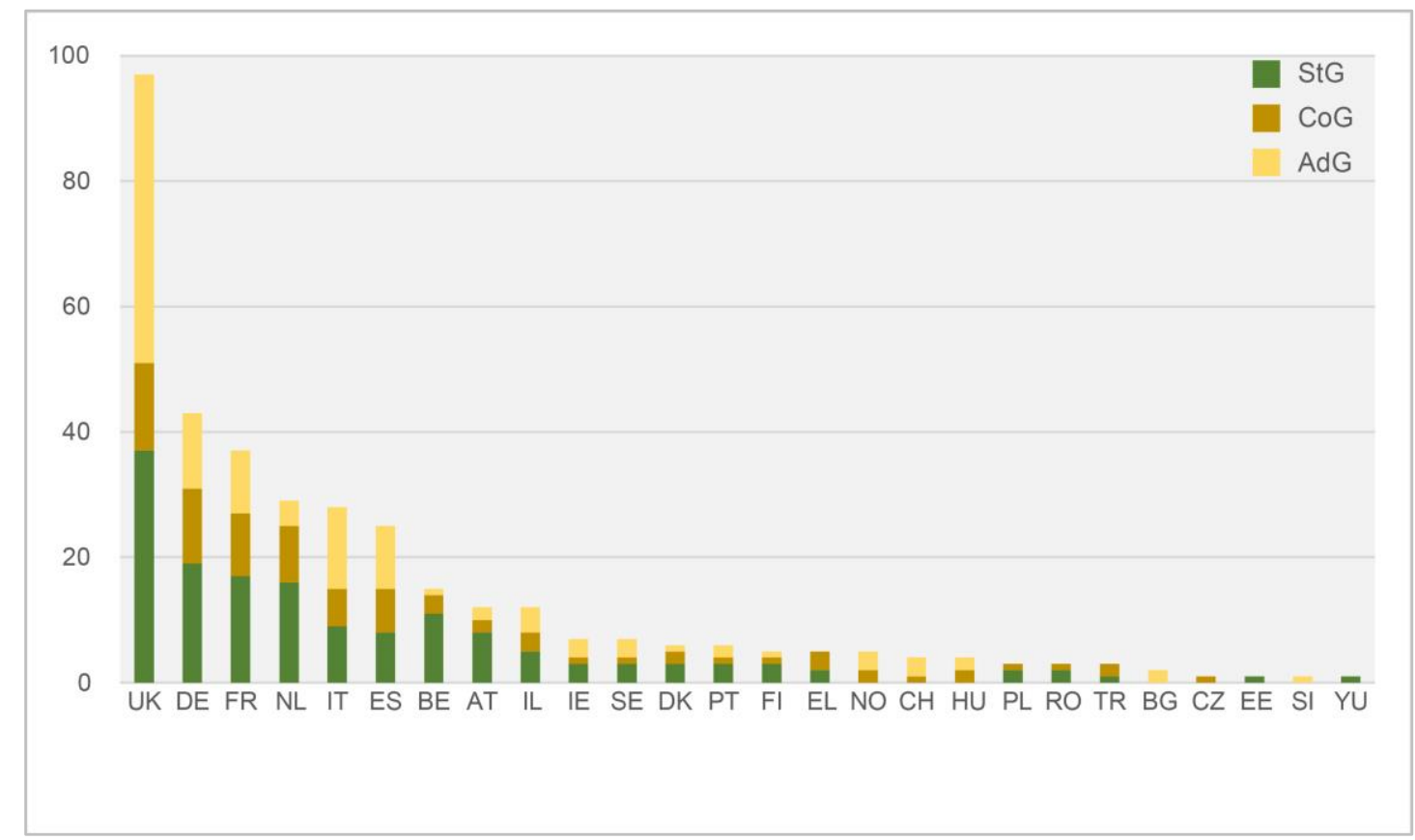

Figure 7. Bar diagram showing the number of ERC awarded by each country in the SH panel, divided by programs.

\section{Small-scale analysis: PIs mobility in SH6 (mobility index)}

We have analysed all the public CVs of SH6 Principal Investigators. 241 of 361 reported all the universities/research institutions attended during the formation years. Based on this sample we tracked the mobility of researchers, in terms of movements between countries and between universities/research institutions. We considered four stages particularly significant: place of birth; place/institution of master's degree; place/institution of $\mathrm{PhD}$; place/institution as $\mathrm{HI}$. Of course, the mobility is forced for those PIs coming from extra-EU or non-associated countries (placed on the top of Fig. 8). Even though there are generally more 'movers' than 'stayers', it is the opposite for British, German (males), Italian (males), French, Belgian (males), Dutch (males) PIs. Probably, in the education of an ERC winner, the quality of the Institution of a country plays a more important role than the established network with foreign Institutions. Further, the gender of the PI seems to play an important role, with a marked female mobility. 
Conversely, there is a high level of internal mobility, with most PIs having attended at least two universities during their education. This has only a few, significant, exceptions. Considering only the major European countries, the only exception are the Italian (males) PIs, with a majority of researchers who won (or brought) the ERC in the same University they attended in all the previous stages of education (Fig. 9).

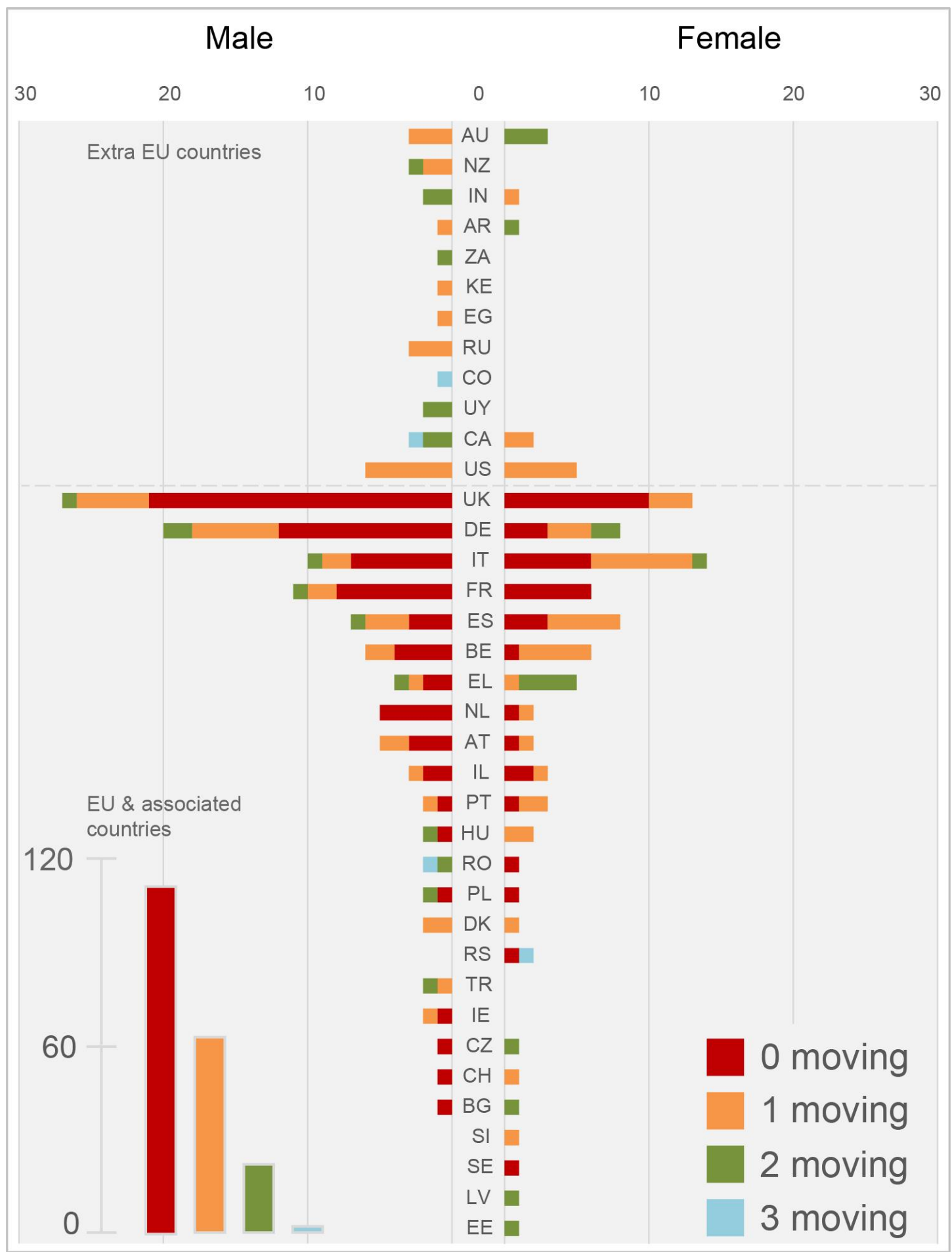

Figure 8. Male-Female mobility of PIs according to country of birth, MA country, PhD country, HI country. 


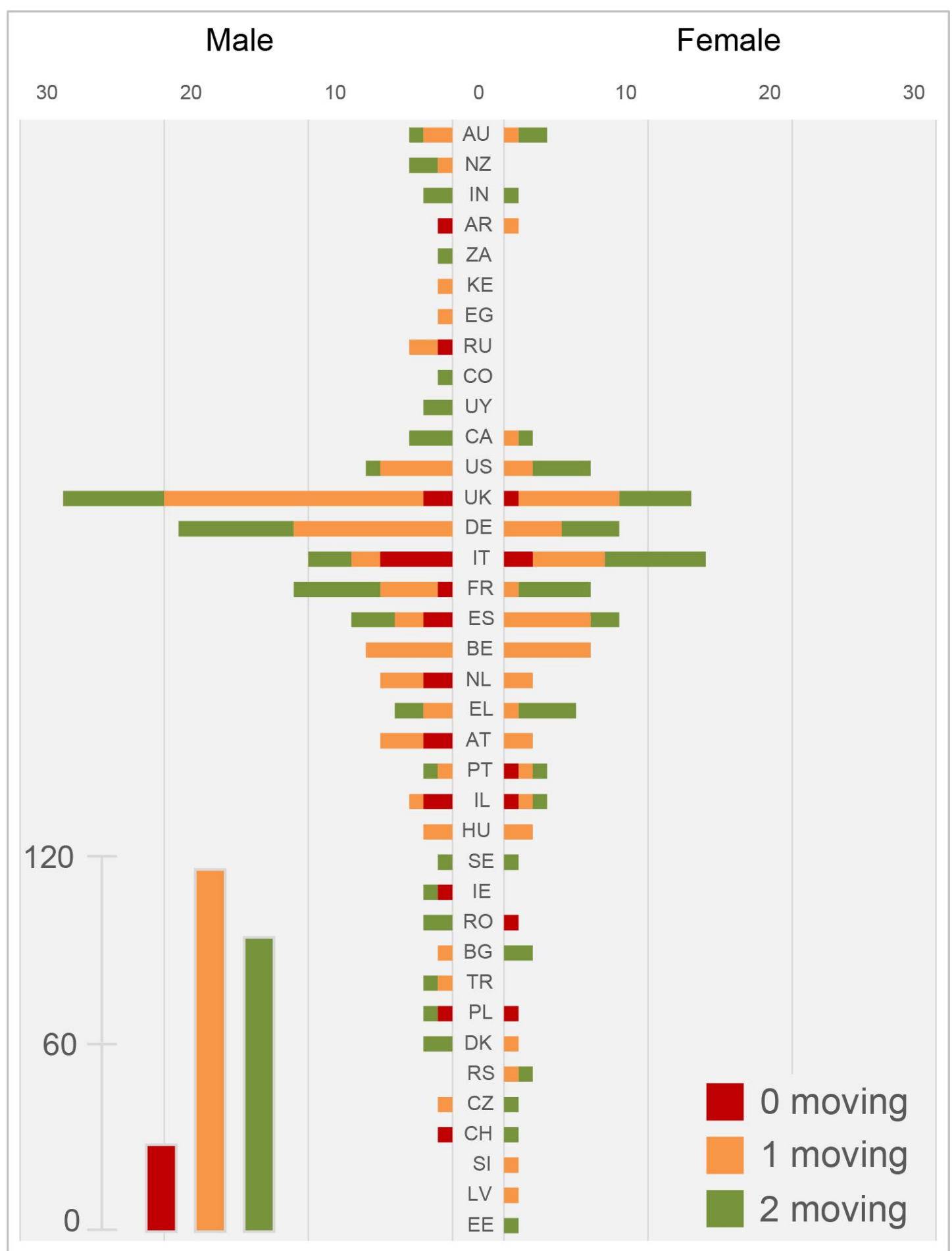

Figure 9. Male-Female mobility across universities of PIs according to: MA university, PhD university, HI university/institution.

Small-scale analysis: main mobility networks in SH6 (attraction index)

Finally, we have drew a diagram of the main movements that Principal Investigators have done, selecting two moving in particular: 1) from the country of birth to the country of the Host Institution and 2) from the country of the university where the $\mathrm{PhD}$ was obtained to the country of the Host Institution. Both the analyses give similar results, evidencing the role of hub the United Kingdom holds. It has the greatest attraction capacity for PIs 
coming from non-EU countries and has more connections than all other countries (Fig. $10)$.

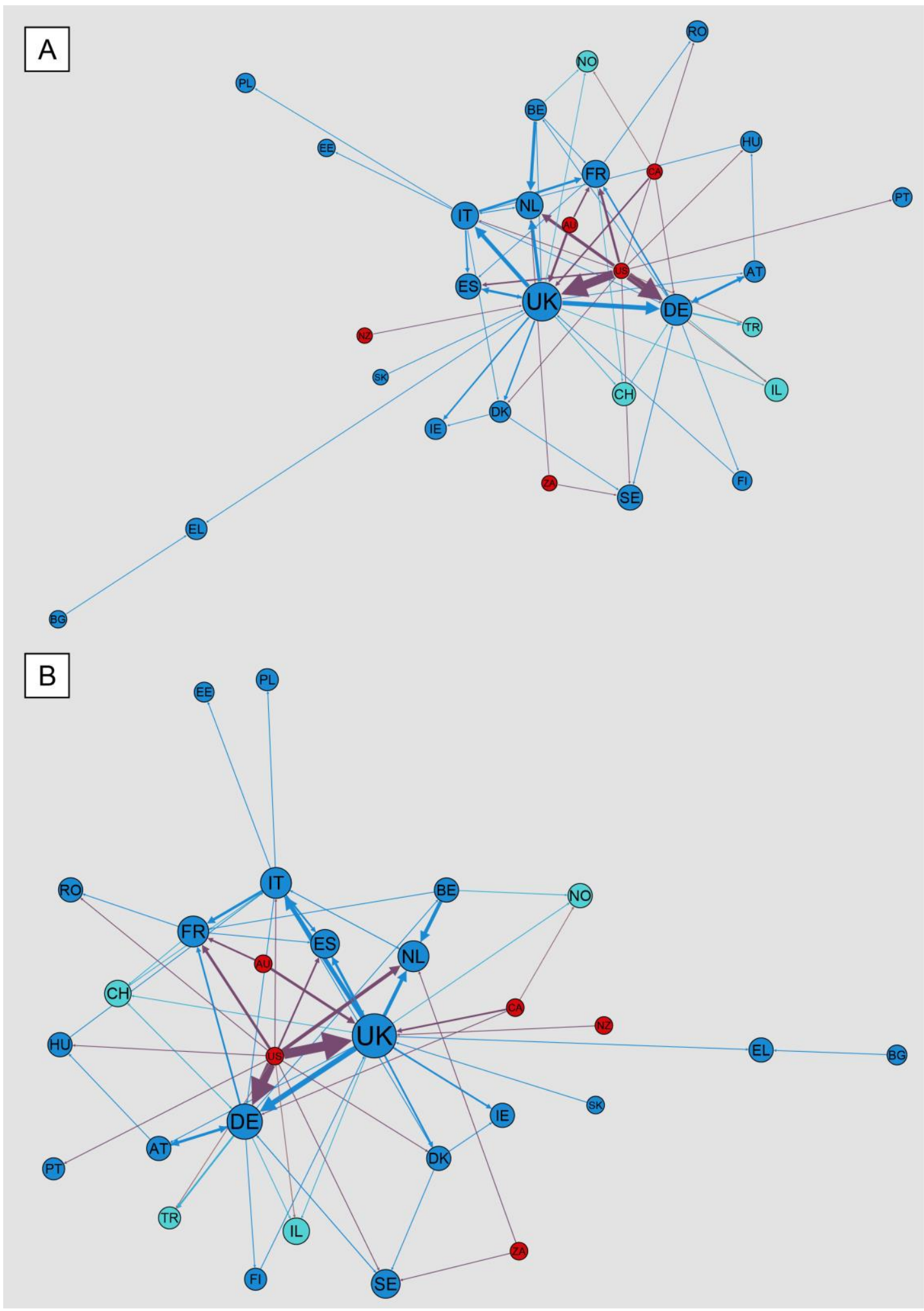

Figure 10. A: connection from nationality of the PI and $\mathrm{HI}$ country. B: connection from $\mathrm{PhD}$ country and HI country. 


\section{SH6 Panellists}

Affiliation (country) and nationality of $\mathrm{SH} 6$ panellists

UK institutions have the highest number of panellists and about one third of the Chairs employed in SH6. They are followed by the institutions of the major European countries, with French, German and Italian ones respectively second, third and fifth place in the rank. US institutions rank highest among non-EU by panel members (Fig. 11). The affiliation data, when compared with the nationality of panel members (Fig. 12), confirm the great ability of UK institutions to serve as a hub for foreign researchers. In this sense, French institutions play an important role as well, while German and Italians seem less attractive - or more reticent - to hire specialists from other countries. US and UK universities and research centres - currently both non-EU countries - provide the half of Chairs and a quarter of the total panel members. Some EU countries have not had - at least during the first fourteen years of ERC - panellists employed from their national institutions (e.g., Slovakia, Romania, Croatia).

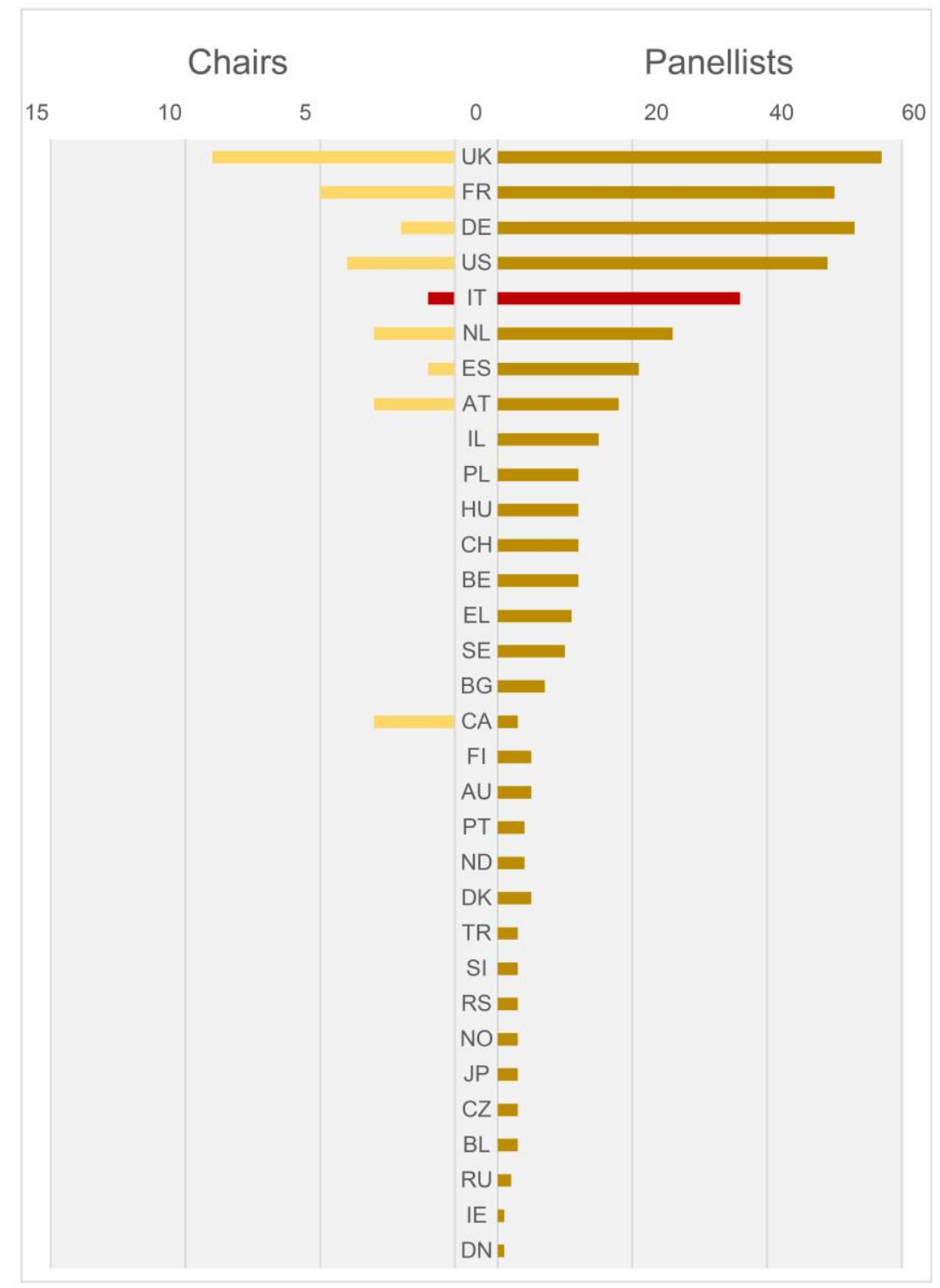

Figure 11. Affiliation (by country) of SH6 panellists and Chairs (2008-2020). 


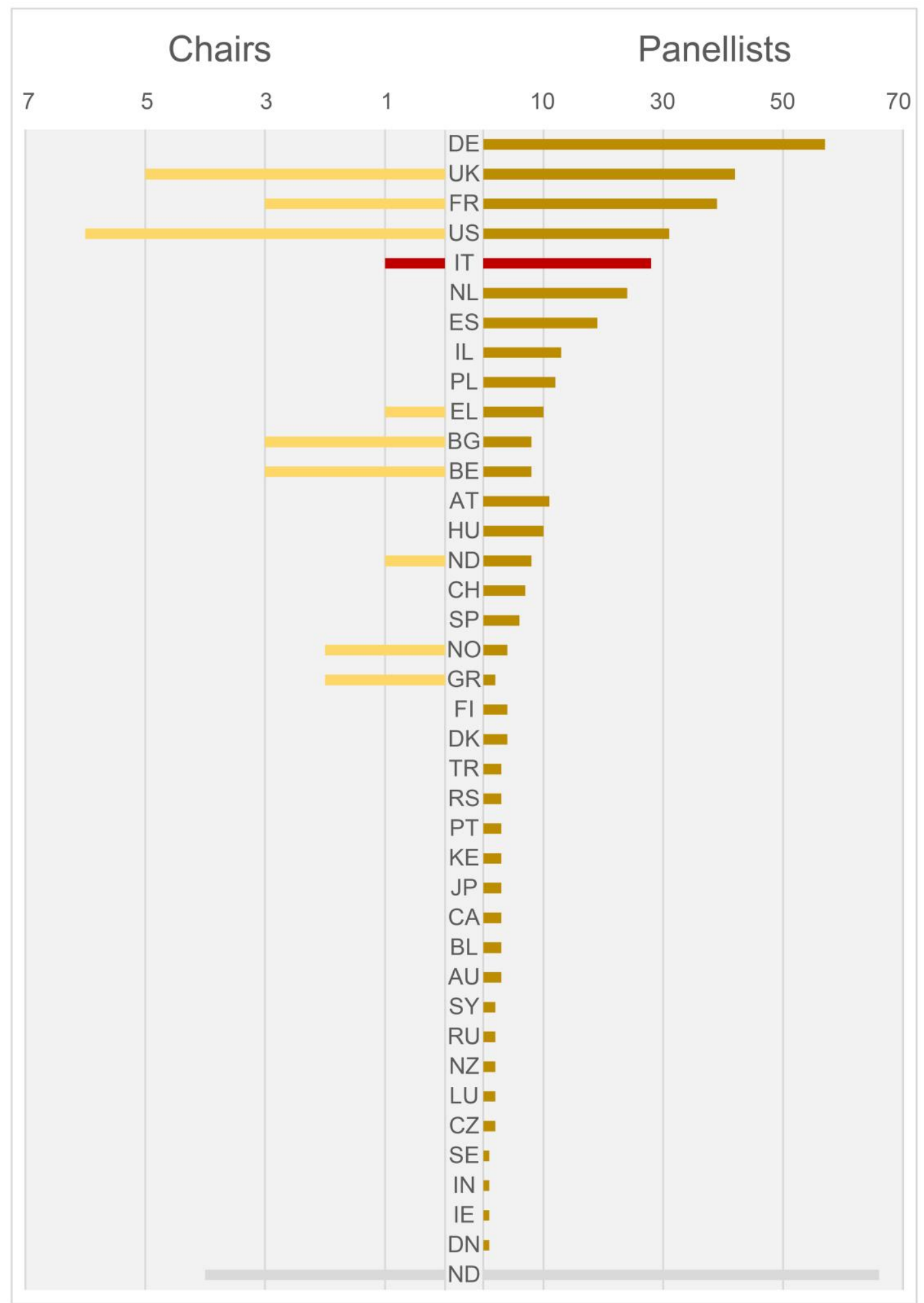

Figure 12. Nationality (birthplace) of SH6 panellists and Chairs (2008-2020).

\section{Affiliation (institution) and composition of $\mathrm{SH} 6$ panellists}

The most frequent panellists' affiliations do not reflect the nationality of the most frequent institutions. For example, the UK institutions are represented as much as the Italians (Fig. 13). SH6 is composed by historians and archaeologists. Two-thirds of the panellists are 
historians, with a high percentage in medieval and modern history specialists. Among the archaeologists there are usually experts of bio-archaeological disciplines (i.e., archaeozoology, physical anthropologists, palaeobotanists, etc.).

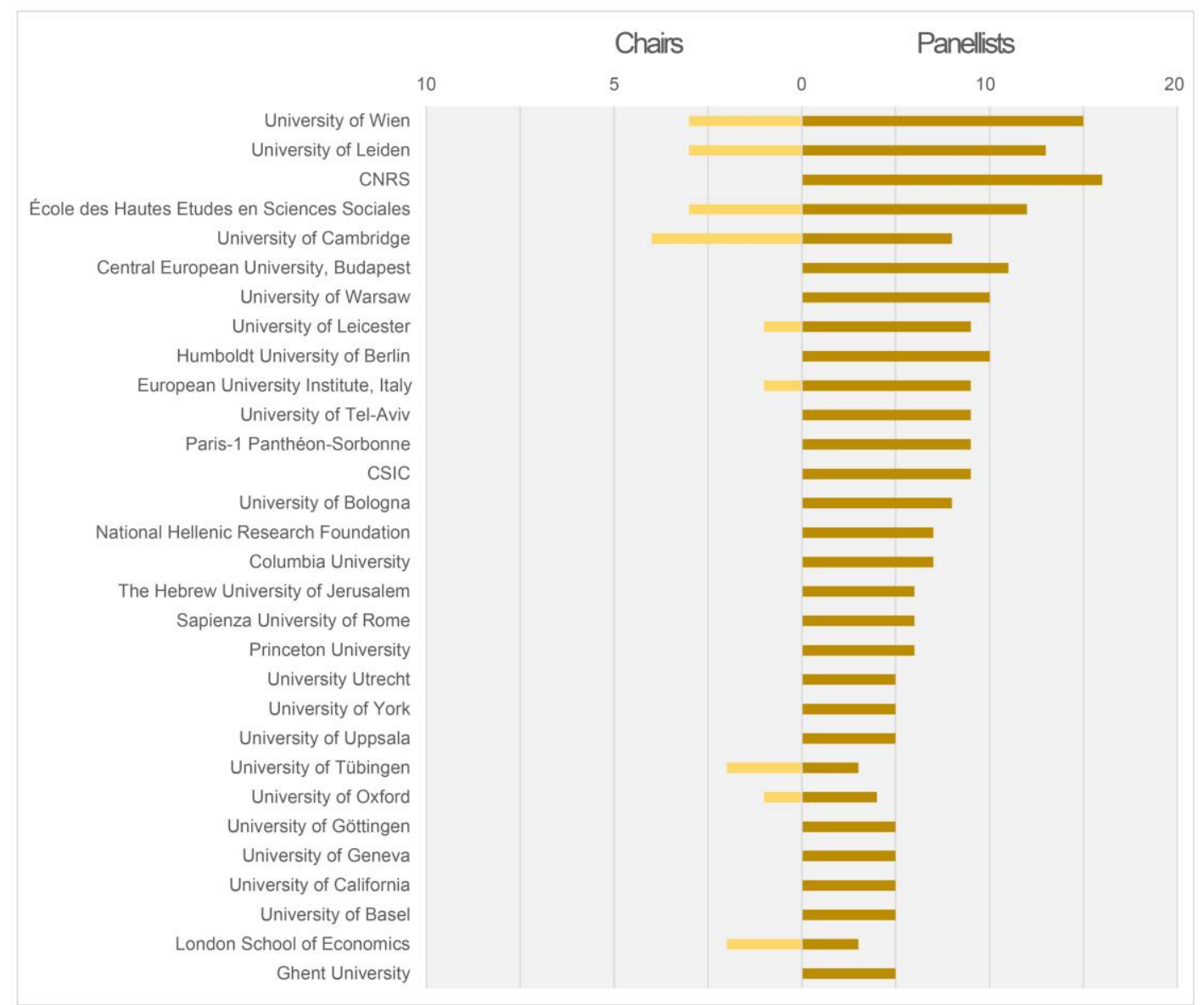

Figure 13. Top affiliations of SH6 panellists.

\section{Panellists and ERC winners: a missed correlation?}

There is apparently no correlation either between panellists' research area and ERC topic or between the nationality of the former's institution with the latter (Fig. 14). It is the demonstration, we believe, that the international composition of panels and reviewers ensures an ethical and no biased evaluation process. Once again, UK institutions are first in the ranking for presence in the panels. Large countries like Germany and France are similar in the number of panel members, still far from the UK. The latter is the only big country with a positive panellist-PI balance. Italian Institutions are the least represented among the major European countries, closer to the Netherlands than France and Germany (Fig. 15). 


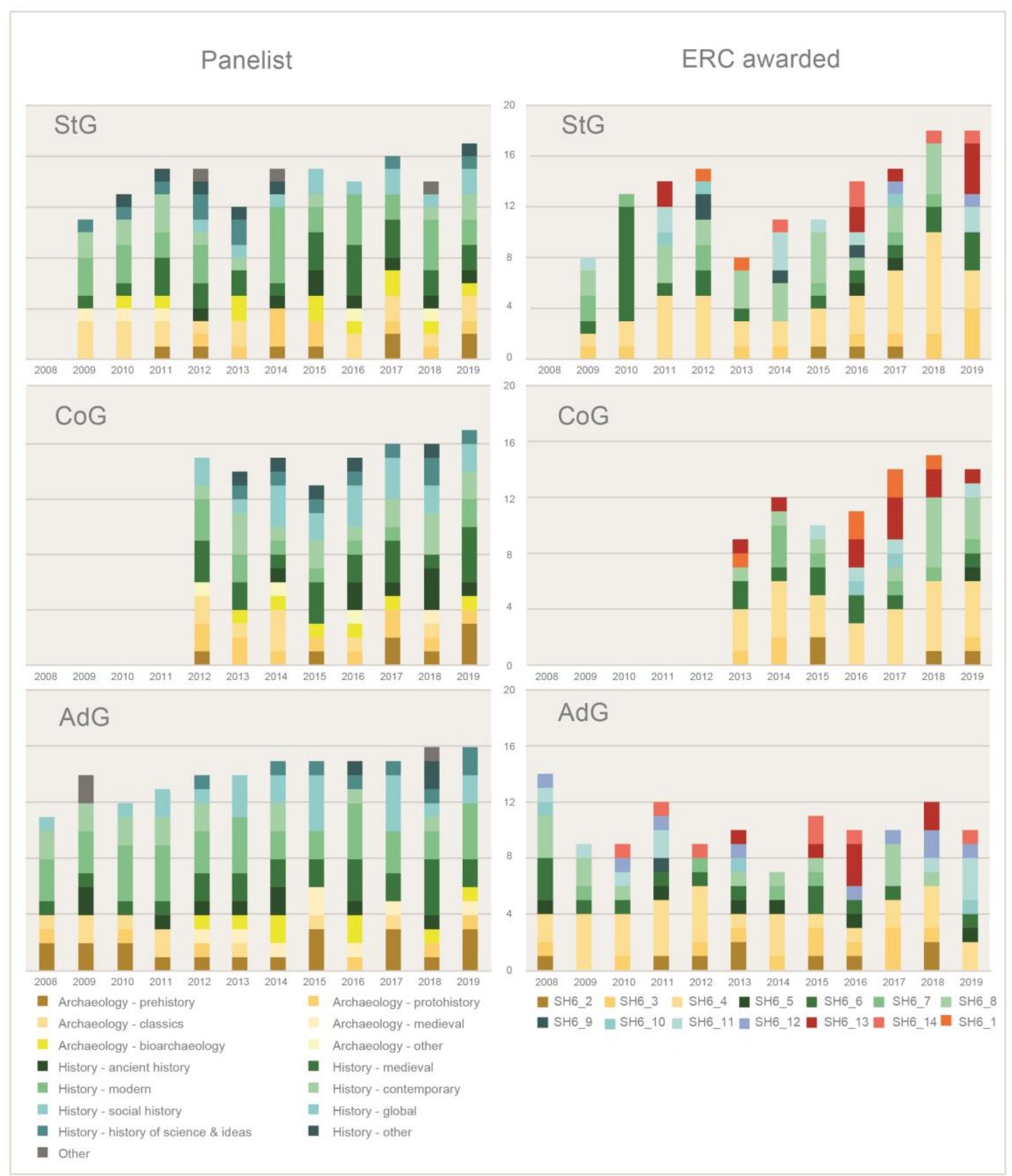

Figure14. Main research interest of panellists and Personal Investigators. SH6 sub-sectors: SH6_1: Historiography, theory and methods in history, including the analysis of digital data; SH6_2 Classical archaeology, history of archaeology; SH6_3 General archaeology, archaeometry, landscape archaeology; SH6_4 Prehistory, palaeoanthropology, palaeodemography, protohistory; SH6_5 Ancient history; SH6_6 Medieval history; SH6_7 Early modern history; SH6_8 Modern and contemporary history; SH6_9 Colonial and post-colonial history; SH6_10 Global history, transnational history, comparative history, entangled histories; SH6_11 Social and economic history; SH6_12 Gender history; cultural history; history of collective identities and memories; SH6_13 History of ideas, intellectual history, history of economic thought; SH6_14 History of science, medicine and technologies. 


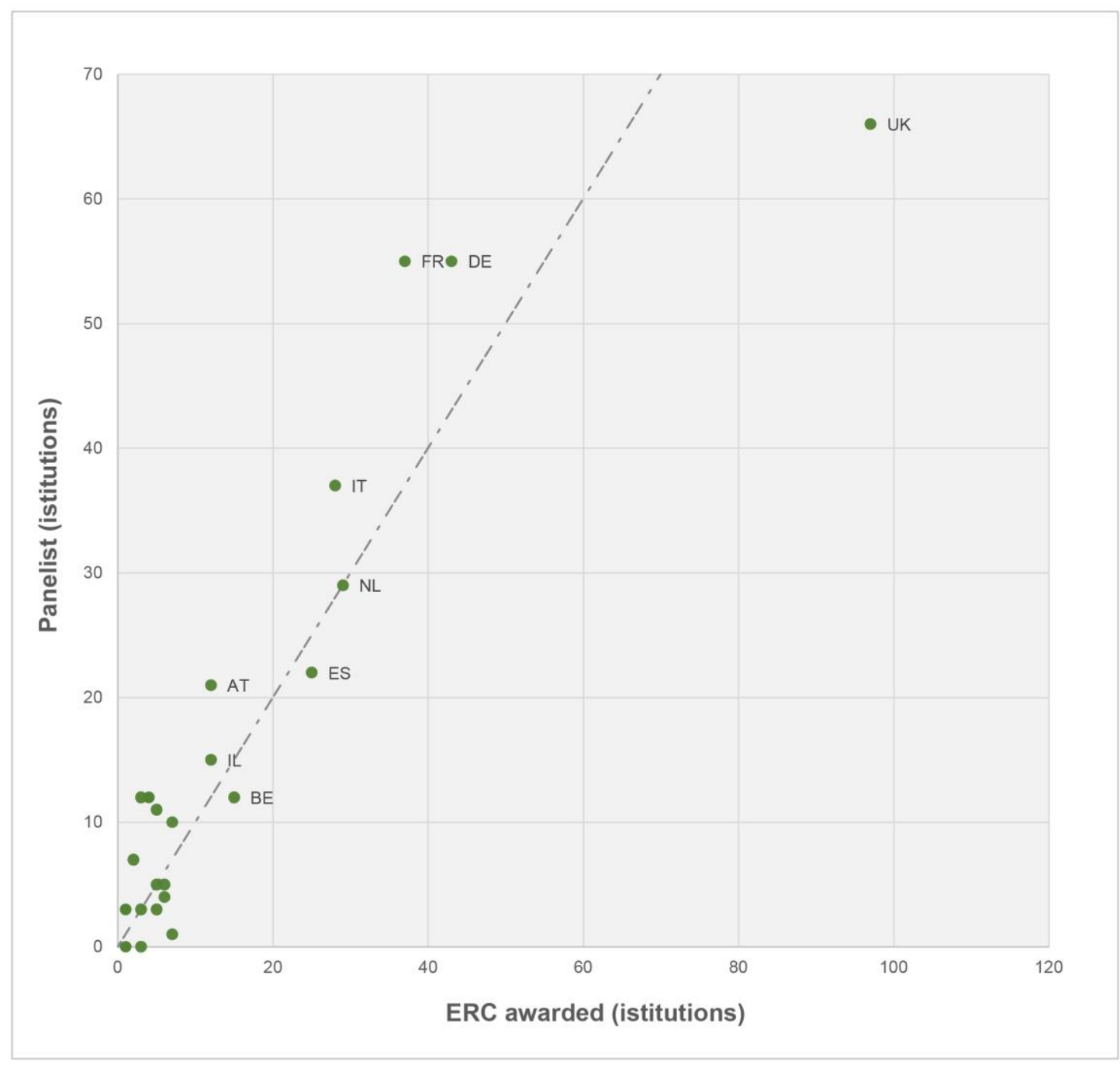

Figure 15. Scatter plot showing the correlation between panel country affiliation and PIs country affiliation.

\section{Anatomy of the ERC projects: the trend topics}

We collected all the summaries that describe the founded projects trying to capture the most recurrent words and themes. We use an R script to transform the texts into a list of words, removing stop words and performing a lemmatization process to group together the inflected forms of the words. Although it is not the most repeated words that characterized specific semantic cluster, the same, some interesting observations are possible analysing the most recurrent 50 words, shown, along with their relative frequencies, in the table below (Table 2).

The most recurrent word, as it was predictable, is history, with ca 730 repetitions; it is compared in more than 300 summaries. It is followed by Europe (variously declined) with 534 repetitions. Some terms refer more or less directly to the methods applied, underling the "scientific approach" used, as the words technology, science, data or (in a more nuanced way) analysis suggest. Another set is constituted by words that remind to the "social", latu sensu, aspect of the historical enquiry: political, economic, society. The word empire (171) and colonial (96) are not so far from the former terms and are linked to the presence of recurrent words related to the geography. Apart from Europe, there are Africa 
(168), followed by east (137, often used in the locution near east), western (117), Asia (106). Religion appears 141 time while Islam (105) is the most recurrent term that refers to a specific religion (Christianity 78, Catholicism 10). Among words that define a specific historical period compare modern (195, often but not only used to define "modern history") and medieval (119). Archaeology is well attested (1/3 ca of history), without any word that specified a single period among the first 50 words (medieval is much more related to history than archaeology). Closely related to archaeological projects is the term environmental, repeated 158 times in 83 projects (ca 25\%); it is a good proxy of the importance that the "biological" approach to history has in European historical and social science and the frequencies of the words that refer to those aspects, like archaeobotany (22), archaeozoology (11) and archaeogenetic (10), confirm this impression.

\begin{tabular}{|c|c|c|c|c|c|c|c|c|c|}
\hline Word & Freq & Word & Freq & Word & Freq & Word & Freq & Word & Freq \\
\hline history & 730 & regional & 246 & $\begin{array}{l}\text { comparati- } \\
\text { ve }\end{array}$ & 182 & source & 142 & material & 114 \\
\hline Europe & 534 & political & 243 & production & 173 & religion & 141 & population & 114 \\
\hline $\begin{array}{l}\text { social/ } \\
\text { society }\end{array}$ & 487 & $\begin{array}{l}\text { econo- } \\
\text { mic }\end{array}$ & 242 & empire & 171 & east & 137 & model & 111 \\
\hline $\begin{array}{c}\text { cultural/ } \\
\text { culture }\end{array}$ & 405 & world & 230 & Africa & 168 & states & 132 & $\begin{array}{c}\text { communiti } \\
\text {-es }\end{array}$ & 110 \\
\hline analysis & 370 & approach & 217 & global & 167 & across & 128 & Asia & 106 \\
\hline development & 316 & data & 208 & $\begin{array}{c}\text { environ- } \\
\text { mental }\end{array}$ & 158 & text & 122 & islam & 105 \\
\hline human & 310 & $\begin{array}{c}\text { methodo } \\
\text {-logy }\end{array}$ & 202 & ancient & 154 & innovative & 119 & identity & 104 \\
\hline $\begin{array}{l}\text { understan- } \\
\text { ding }\end{array}$ & 304 & modern & 195 & system & 148 & medieval & 119 & wars & 98 \\
\hline $\begin{array}{l}\text { archaeolo- } \\
\text { gical }\end{array}$ & 271 & science & 194 & process & 143 & past & 117 & colonial & 96 \\
\hline change & 266 & $\begin{array}{c}\text { technolo } \\
\text { gy }\end{array}$ & 189 & context & 142 & western & 117 & trade & 95 \\
\hline
\end{tabular}

Table 2. Most frequent words by summaries of SH6 awarded projects.

However, a more detailed analysis is needed that considers the entire content of the summaries of each project is necessary. First, we classified the projects description using four labels: 1) the ERC sector (Fig. 16), where chronology and themes are not always distinguishable; 2) a chronological label that considers the period on which the project focuses; 3) a label describing the area of interest; and 4) a topic label that describes main topics of the project. While for the formers labels a dictionary has been used, the second was more descriptive and, to some extent, emerges from the keywords we assigned to each project. 
Although not rarely it has been difficult to assign a project to a single ERC sector, an immediate consideration arises simply by counting the number of projects that falls into each category: history counts 241 (about 60\%) projects (Prs), archaeology 146 Prs (about $40 \%$ ), with a high frequency of prehistoric research. Medieval and contemporary history are well attested discipline (respectively 48 Prs and 49 (Prs), while ancient history is probably underestimate because it often overlaps with classical archaeology.

In historic domain it is not uncommon the occurrence of projects focused on scientific issues crossing large periods and areas. They have been grouped under branches such as social and economic history, history of ideas, intellectual history, history of sciences (17 Prs); or social historical studies such as gender history, cultural history, history of collective identities and memories (14 Prs).

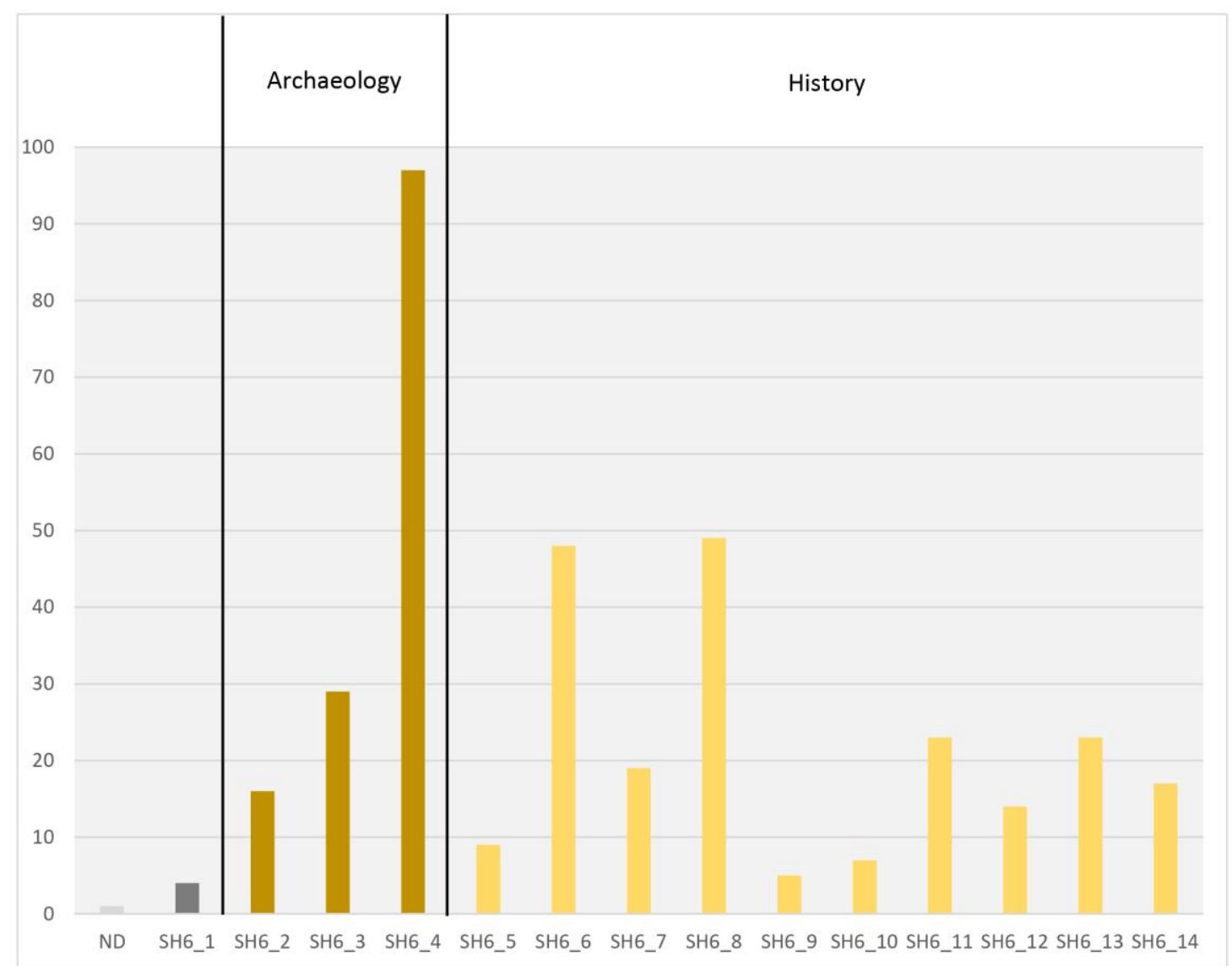

Figure 16. SH6 sub-sector of ERC granted projects.

This data can be more in-depth explored further by using our chronological labels, where only period ranks the projects (Fig. 17). The most studied periods are prehistory (100 Prs - 27\%) and contemporary (77 Prs - 21\%), followed by the Middle Age (64 Prs - 17\%). It is even more significant when it comes to major research subjects. A content classification is a very complex task, being based on subjective decisions, depending on the knowledge we have of the subjects. We assigned keywords to the summaries to extract the themes i.e., the project main topic (PrMT) - from the keywords. As a result, although a single project may fall under more than one PrMT, the major PrMT is generally well perceived. Prehistory projects mainly deal with ancient prehistory, focusing on three PrMTs: human 
evolution, human - environment relationships and agriculture (especially the spread of agriculture). 'Agriculture' is the PrMT of 22 prehistoric projects, focusing on Neolithic times. Almost all the projects addressing these issues are based on bioarchaeological techniques, in particular aDNA analysis and/or stable isotope analysis (36\% of the prehistoric Prs, 9 Prs pertaining other periods have the same approach). Very rare are the archaeological projects that place excavation as the core of the research (only 7), while the study of the material culture, even if is always mentioned, is the core subject of only 2 Prs. The importance given to the environment is also found in projects that focus on later period, 12 Prs directly deal with environmental issues and the other 22 Prs explore the transformation of the landscape during the times. In general, themes of projects on historical periods are more nuanced. Historical transformation is obviously the common matrix of most of the projects but still some specific trends can be discerned. The study of corpora of texts or ancient archives (including palaeographical and philological enquiries) is a well attested topic with 34 Prs, 13 of which relate to the Middle Age. Another frequent topic is religion with 22 Prs that principally focus on it; they mainly concern Middle Age (11 Prs) while Islam is the most studied (8 Prs). Human mobility, migration and the concept of borders have a predominant role in 20 Prs. Colonialism is another "hot-topic" (15 Prs) that partially overlaps with Slavery (9 Prs). The study of jurisprudence is central to 20 Prs (10 related to Contemporary Period). As shown in the graph (Fig. 16), 17 Prs address history of science, among them 12 concern the history of medicine.

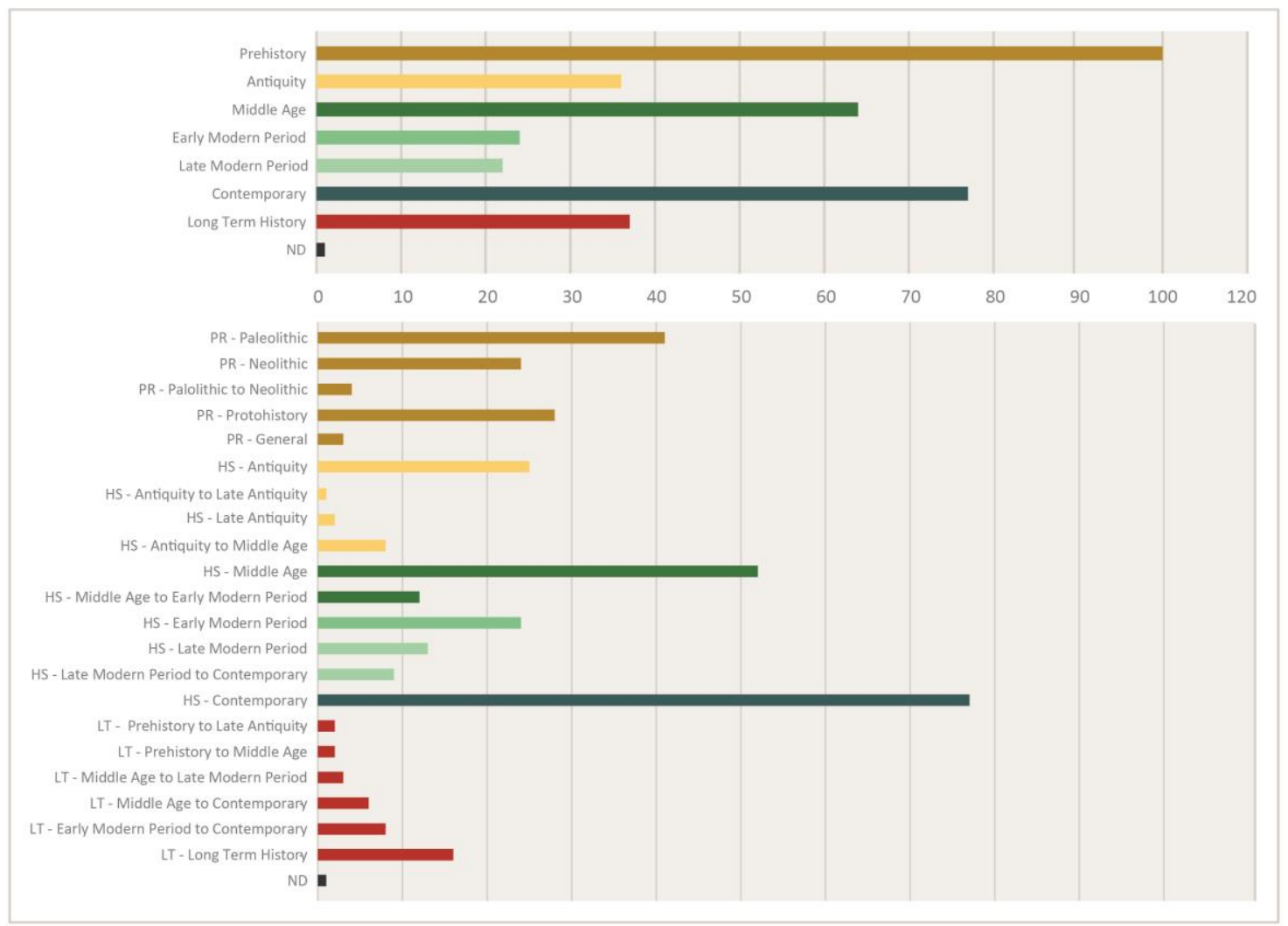

Figure 17. Chronological framework of ERC granted projects in SH6.

The geographical focus of the project can further inform our analysis. Two aspects can be considered: the extent, calculated on the following scale, micro-region, macro-region/sub- 
continental region, continental scale, over continental scale, sub-global or global; most frequent areas. Most Prs deal with wide areas, roughly corresponding to a continent (more precisely to a part of it but with not a clear specification, e.g., "... within their wider European context...”) with 235 Prs; 35 focus on specific region, while only 17 Prs specify a macro region; 68 Prs consider wide areas (phenomena observed among different continents or worldwide). Most studied area is Europe (165 Prs), followed by Asia (132 Prs). Among the micro or meso scale, Egypt is the geographical context that has been most frequently addressed (10 Prs).

It clearly emerges that some research topics are more rewarded. First, the large number of prehistoric projects is surprising. It does not correspond, for example, to the composition of the panels, where the majority of scholar are historians, rather it seems the nature of the discipline that, by allowing an approach using hard science methodology and addressing broad issues such as human evolution (physical and/or cultural) or agricultural spread, has been rewarded. Also questions strictly related to contemporaneity seem to be more appreciated than others, such as the study of large archives or corpora that offer new data for historical enquiry. However, in order to have a complete collection of reference data, the rejected proposals would have to be analysed as well. In general, projects are extremely uneven, as shown by the difficulty of classifying them demonstrates (see also the graphic impact of the word cloud by summaries: Fig. 18).

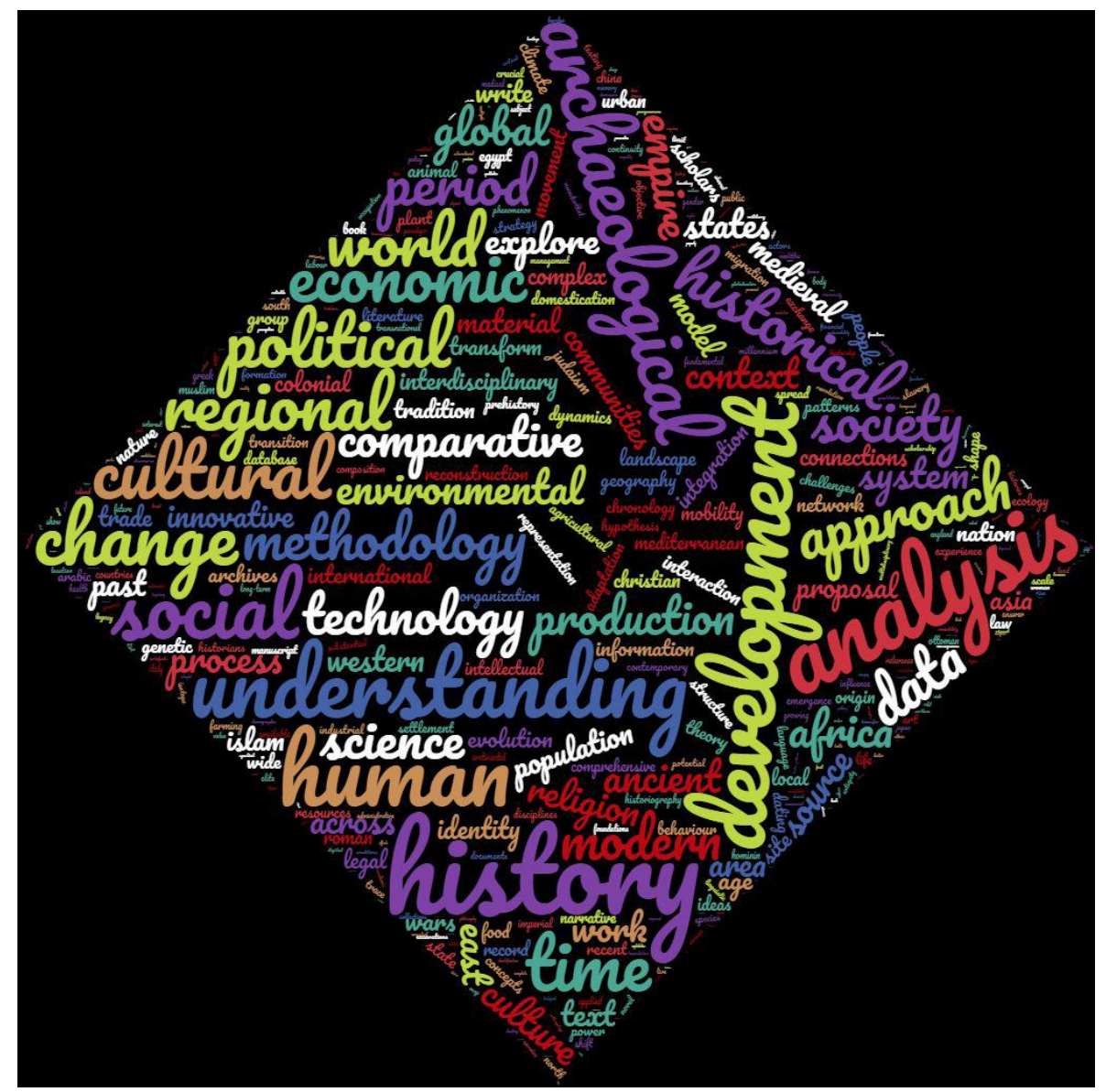

Fig. 18. Word cloud by summaries of SH6 granted projects. 


\section{Degree of ERC knowledge in Italian universities}

The last analysis we show is a survey we conducted in the summer of 2021. We shared an online survey starting from our networks (mainly Sapienza University of Rome), addressed to students at various stages of their training, graduate scholars, PhD candidates and postdocs. Finally, about 80 participants attended, mostly archaeologists with a few historians (Fig. 19).

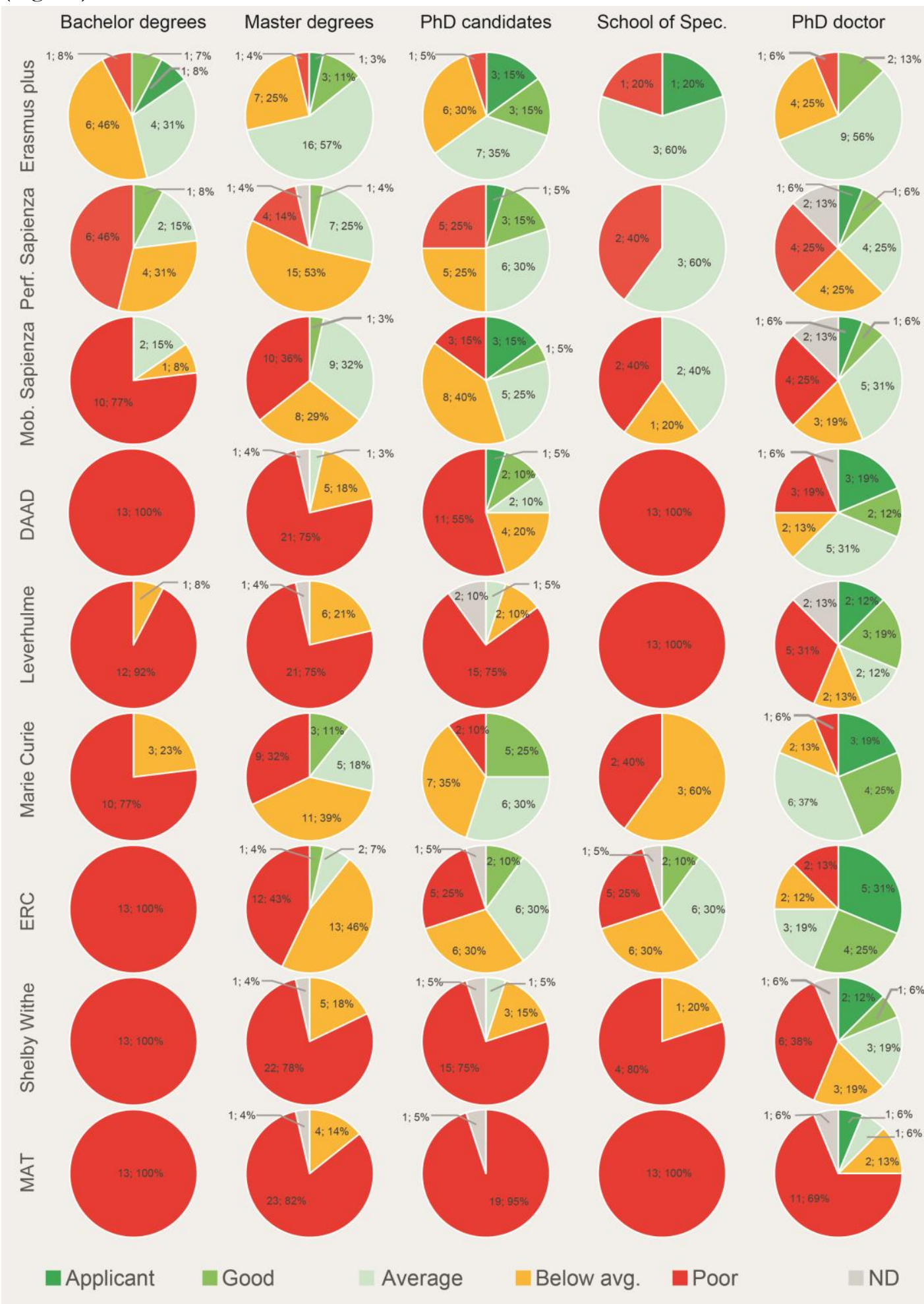

Figure 19. Pie chart of the survey on the degree of knowledge of European and Italian research grants. 
As a result, we found most of master's students do not know, or have only a vague idea, of the main grants to apply once they graduate. The knowledge of ERC grants and other important post-doc grants - such as the Marie Skłodowska-Curie, the Leverhulme Trust - is very low among the $\mathrm{PhD}$ candidates. Further, generally very few apply for mobility grants. Probably, the same survey if proposed to other Italian universities would give similar results. The scarce general degree of awareness of European grants is partly due to inadequate strategies of information. Indeed, if on the one hand it is absolutely legitimate not to apply for grants implying mobility, on the other hand, it is a specific duty of the Institutions to provide all the necessary information to pursue research. In this sense, especially in the last few years, there is a growing effort to organize webinars and meetings aimed at future or young researchers.

\section{Discussion}

There are structural reasons that make some countries more competitive than others in the funding competition. First, a country's wealth and attitude toward R\&D funding affect the quality of research institutions. The best institutions - and the countries more predisposed to the integration of foreign researchers - attract more ERC projects, further increasing their prestige. One of the most interesting data emerges from the mobility of PIs at various career stages. While - in particular for male PIs - there is not a high mobility from a country to another, it seems to be quite common to change universities during the education or in the early stages of research career. Italian researchers have the lowest rate of mobility between institutions (particularly males, but in absolute terms it is also true for Italian females). We believe the low mobility is one of the factors that limits an early and full independence of aspiring PIs. Not least, it prevents personal networking with other researchers external the main institution.

The independence of the PIs is a very emphasized point in ERC calls and, as reflected in Lapini's article cited above, the current Italian researchers' recruitment system does not favour either the mobility between countries and universities or an early independence of young researchers. It is probably not a coincidence that Italian researchers have the worst performance in the Starting and Consolidator grants, while Italian PIs are 2nd in the rank of Advanced grants. A further important consideration emerges by the nature of the ERC, as it is conceived, which is reflected in the projects awarded. ERC grants favour the emergence/confirmation of independent researchers rather than supporting long-lasting and already rooted research in specific academic contexts. A good example, based on our specific expertise, can be drawn using the data analysis of archaeological awarded projects. As we have noted, excavations are very rarely proposed in the awarded projects. This kind of activities usually involve a large group of people (far beyond the scientific team that every ERC project considers) and needs a timing greater than the duration of an ERC. In addition, excavations, the main source of archaeological data, are enquiries that do not necessarily supply the data needed - literally searched - while the funded projects have to be successful within the given deadline. It seems that the common matrix of the awarded projects coincides with a well-defined research question, the competence of the researcher in the field (who must be a specialist) and the "seek and destroy" attitude. 
Other factors influencing competitiveness concern the awareness of the existence of financing opportunities for academic research and, as the survey results show (see section 4.4) there is very little awareness of the main European funding opportunities (Graph. 19). One of the recurrent arguments posed by Lapini concerns the quality of the founded research. The author is very sceptical about the selection process, in particular he focuses on two distinct aspects: 1) project validity does not depend entirely on the research questions but rather on addressing trendy topics, such as "gender" or "sustainability", and by the use of an appropriate language, a sort of "ERC jargon" that uses an undeniable a set of words; 2) panellists are often not specialists in the subjects they have to evaluate (probably he refers to the wide range of topics addressed by the proposals in each scientific sector that would make it impossible the constitution of a panel with the right competences). This would be the reason why universities, looking for the income that an ERC guarantee, offer specific “... courses, cycles of lessons, in which they help you package your project by choosing the most intriguing title, the coolest acronym, the coolest formulas, designed to impress the evaluators". Regarding, this last consideration, we think it goes without saying that aspiring researchers should be able to write projects. As for the other criticisms of ERC grants, particularly the evaluation procedure, some appear quite difficult to sustain. The panel members include some of the best and most influential experts in the various disciplines, selected by the ERC Scientific Council based on the academic reputation. The evaluation process relies on the combined judgment of external reviewers. Indeed, while the panellists are 'generalists', the external referees are selected on the basis of specific expertise on the subject of the proposal. The evaluation procedure is highly articulated, and it is very difficult - we believe impossible - to evade all quality controls simply by using vogue words. Moreover, based on the analysis proposed above (section 4.3) there is no clear evidence of this phenomenon.

Finally, network analysis, the most awarded 'countries', and panel compositions - with particular attention to the affiliation of the Chairs - outline English speaking countries as leader in the research field. While this is not so surprising by considering the rank of US and UK institutions on a global scale, the only way to close the gap is a more conspicuous internal expenditure on the $\mathrm{R} \& \mathrm{D}$ sector, in order to improve quality and competitiveness of research and researchers. We have no doubt about the influence that the large presence of commission members from leading research countries - as UK and US are undoubtedly - have a role in the success of certain methodologies, research approaches and research interests at the expense of other ways of conducting basic research. However, the ERC has a bottom-up approach, opened to promoting research that is usually outside of the general guidelines and already established research thematic and methodologies. Therefore, it should not be intended as an integration to structural funding, but rather as an opportunity to conduct well defined innovative research. Conversely, part of the structural funding should be invested in training and supporting aspiring ERC winners.

Since there is no reason to doubt the quality of the research and researchers awarded with the ERC grants - as well as the absolute competence of the panellists -, the ranking of most awarded countries may be intended as the touchstone for the health of the research in a country. 


\section{Conclusion: The European research toward a paradigm-shifting}

From the 7th framework programme, a new season of academic research has begun in Europe. Competition with non-EU research programs to engage brilliant researchers from other continents has had so far in SH6 a low impact, though better than none. Moreover, the only country whose institutions attract a certain number of non-EU ERC winners is the UK. At the same time, the coveted Eurozone is still far from being realized. European institutions are not interchangeable, and some (few) countries have a magnetic capacity, while others can barely hold their researchers. In this context, Italian institutions surely cannot refuse to host ambitious and quality research and researchers.

Whether, as we think, the state of research in a country should also be measured based by the competitiveness that its institutions have outside the national borders, then the number of awarded HI and panellists' affiliation should be considered a significant parameter. We believe that Italian institutions could - and should - have better results in terms of hosted ERC grants, also considering the very low success rate - hence the high number of 'Italian' proposals evaluated -, far below the major countries and also below the European average (Graph. 4). Since the Starting Grant is the call in which Italian institutions are least successful, it is perhaps the point on which more attention should be paid on. We believe that young researchers are penalized by the current system of recruiting researchers - which implies the respect of a 'queue', as unintentionally denounced by Lapini - as well as by the absence of well-planned opportunities to pursue the research in Italy as post-docs. These factors delay, if not completely prevent, the achievement of the early 'status' of independent and quality researchers.

To conclude, we think the only way to increase the number of hosted grants is to change the current selection policy and invest funds in tools aimed at supporting the preparation of ERC proposals. Quality, competitiveness and attractiveness of institutions are factors strictly related and they can only increase by catching as many brilliant researchers as possible, even when it means bypassing the 'queue'.

\section{Acknowledgments:}

We would like to thank all the students, graduate students, PhD candidates and researchers who replied to the survey. Additionally, our gratitude goes to Annamaria Daniele, Arianna Durante and Giorgia Sposini for sharing the survey among their personal contacts. Finally, we would like to thank Adriana Altamura for the linguistic corrections.

\section{Author Contributions:}

The authors equally contributed to the manuscript. 


\section{References}

Billari F. C., Verona G. (2020, 7 gennaio), Finanziamenti Erc, il coraggio di premiare l'eccellenza, Corriere della Sera.

Briguglia G. (2020, 6 gennaio), Il ritorno della casta dei poverini?, Il Post (Blog). Accessed 15 Oct 2021, https://www.ilpost.it/gianlucabriguglia/2020/01/06/il-ritornodella-casta-dei-poverini/

KÖNIG T. 2016, Peer Review in the Social Sciences and Humanities at the European Level: The Experiences of the European Research Council, in: OchSNER M., Hug S. E., DANIEL HANs-DiETER (eds.), Research Assessment in the Humanities: Towards Criteria and Procedures, Cham 2016, pp. 151-163. DOI: 10.1007/978-3-319-29016-4_12

LAPINI W. (2020, 4 gennaio), Quei superfinanziamenti che sconvolgono gli atenei, Corriere della Sera.

Nowotny H. 2009, Frontier Research in the Social Sciences and Humanities: what does it mean, what can it mean?, ISSC-ICPHS workshop, Bergen 11 May 2009. http:/ / www.helga-nowotny.eu/downloads/helga_nowotny_b1.pdf.

WINNACKER E.L. 2009, On Excellence through Competition, European Educational Research Journal, 7(2), 2008, pp. 124-130. DOI: https://doi.org/10.2304/eerj.2008.7.2.124 
184 GIANCARLO LAGo \& ANDREA DI RENZONI 